\title{
Anais do I Congresso Acadêmico de Práticas Integrativas e Complementares em Saúde (ConAPICS) Brasil 2020
}

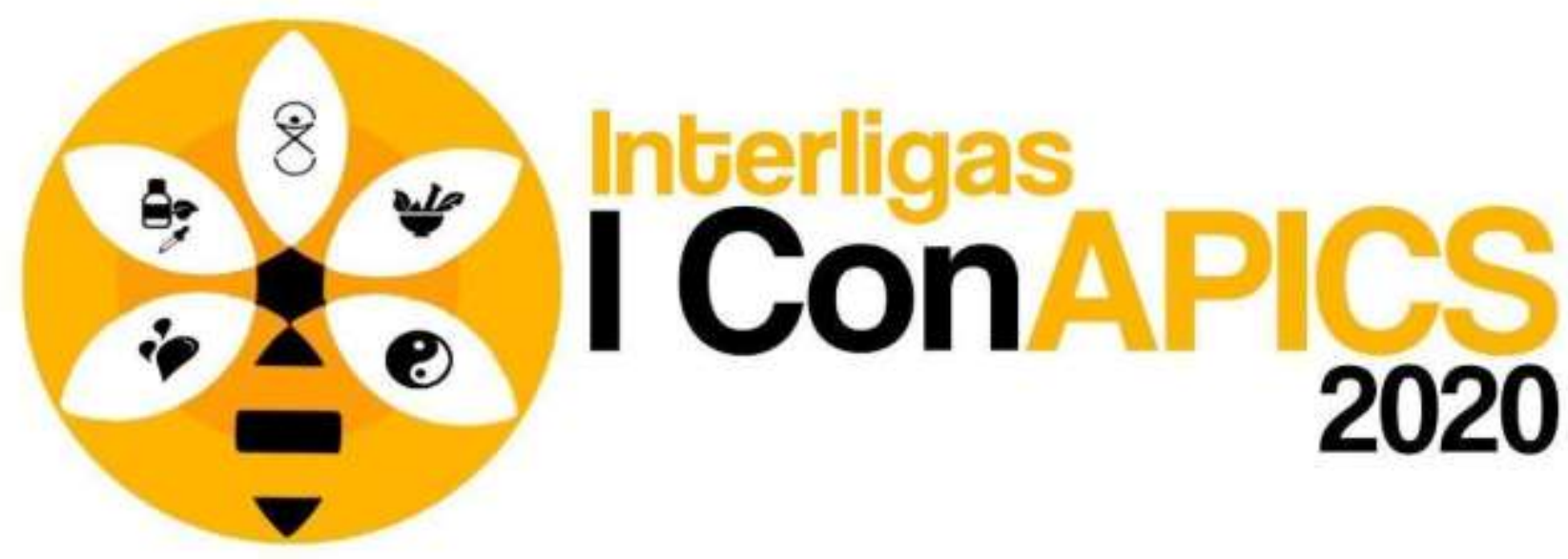

Apoio:
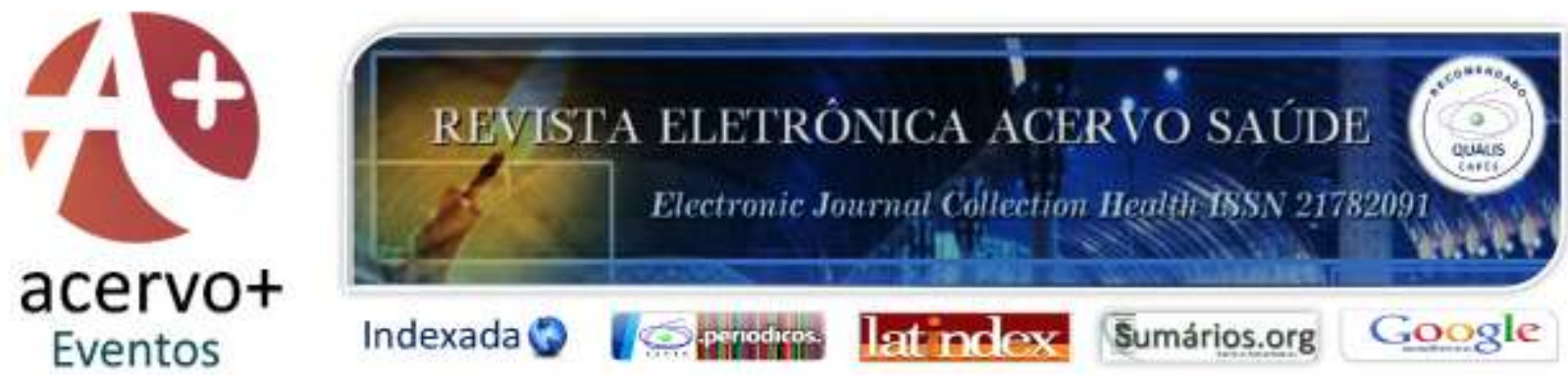


\section{Sumário}

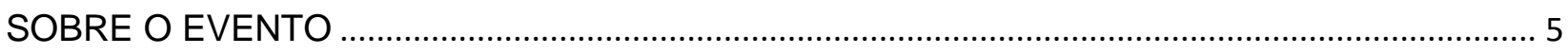

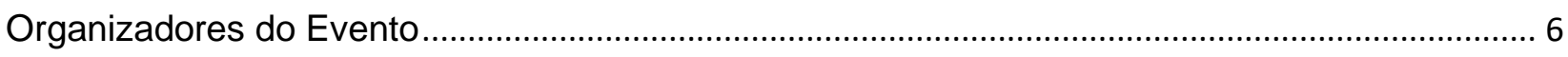

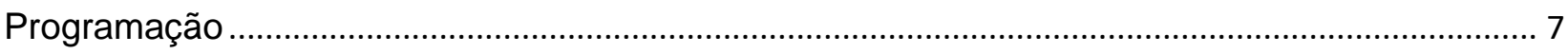

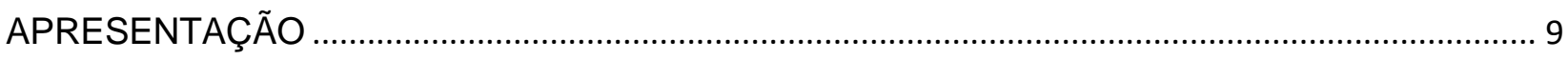

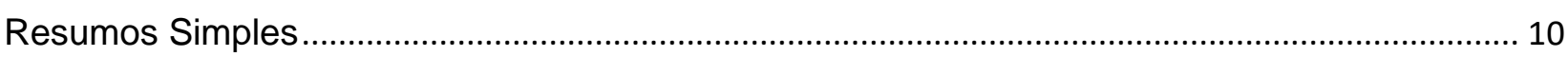

Título: A Mindfulness na prevenção de transtornos alimentares .................................................... 10

Título: A Prática de Yoga durante a Pandemia: Relato de experiência .......................................... 12

Título: Disciplina Felicidade, a inclusão de Práticas Integrativas e Complementares na

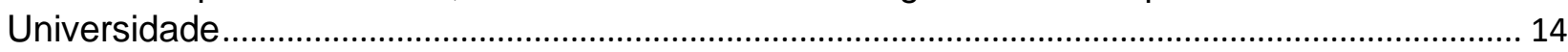

Título: Ozonioterapia como adjuvante ao manejo da fibromialgia: uma revisão integrativa......... 16

Título: Benefícios das Práticas Integrativas e Complementares no controle da dor em pacientes

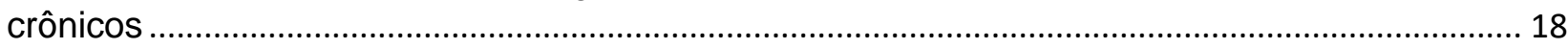

Título: Experiências de estudantes de medicina acerca do ensino das práticas integrativas e complementares aplicando as metodologias ativas...................................................................... 20

Título: Efeito do Silexan sobre o sono: uma revisão bibliográfica .................................................. 22

Título: Aromaterapia no tratamento da Dismenorreia Primária: uma revisão sistemática ............ 24

Título: Práticas Integrativas e Complementares: Conhecimento, utilização e eficácia dos

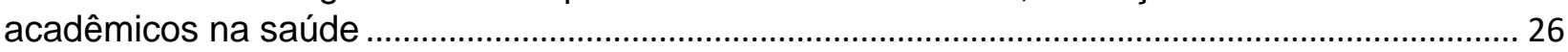

Título: Uso da Valeriana officinalis para tratamento de distúrbios do sono: revisão integrativa.. 28

Título: As tecnologias digitais como ferramenta de Educação em Saúde e divulgação das PICS:

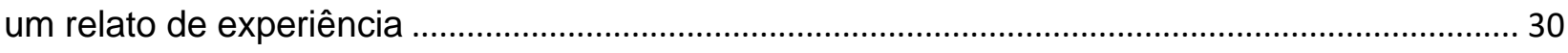

Título: O uso clínico da apiterapia através das propriedades antibacterianas do mel

Título: Relato de experiência da fundação de uma Liga Acadêmica de Medicina Integrativa em uma faculdade federal do Rio de Janeiro.

Título: Medicina Tradicional Chinesa e sua relação com o tratamento de COVID-19: revisão integrativa.

Título: Relato de experiência da publicação de infográficos sobre o uso de plantas medicinais com potencial de uso no tratamento complementar do diabetes.

Título: Formação e Capacitação em Reiki: Um relato de experiência de estudantes membros de uma Liga Acadêmica de Práticas Integrativas e Complementares

Título: Experiência acadêmica da aplicação da Prática Integrativa Reiki através de um projeto de extensão 
Título: Uso da Erythrina mulungu como terapia complementar para ansiedade sequente da pandemia de COVID19 na zona rural do Agreste Pernambucano .................................................. 44

Título: Benefícios da aromaterapia com óleo de lavanda na redução da ansiedade ..................... 46

Título: A acupuntura como prática integrativa e complementar no tratamento de doença pulmonar obstrutiva crônica

Título: O Yoga como prática Integrativa e Complementar na recuperação de pacientes idosos acometidos pelo novo Coronavírus . 50

Título: Importância da acupuntura no tratamento da COVID-19.................................................... 52

Título: A Terapia floral no controle do medo e ansiedade na Odontopediatria............................... 54

Título: Terapias Complementares na promoção da saúde e apoio social no contexto universitário.. 56

Título: Programa de Mindfulness durante Isolamento Social provocado pela pandemia do SarsCoV-2: um relato de experiência. 58

Título: As Práticas Integrativas e Complementares de Saúde (PICS) no alívio da dor crônica em

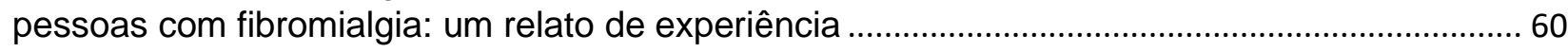

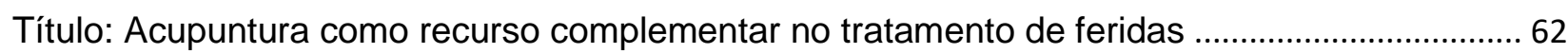

Título: Impressões de discentes de medicina acerca da terapia comunitária integrativa como dispositivo para formação e prática médica ampliadas. . .64

Título: Efeitos do Ginkgo biloba em pacientes com Acidente Vascular Encefálico: uma revisão integrativa...

Título: A aplicação da Medicina Tradicional Chinesa no manejo da COVID-19. 68

Título: As Práticas Integrativas e Complementares como dispositivo no cuidado de si de mulheres vítimas de violência: uma perspectiva da Terapia Ocupacional... 70

Título: Meditação na formação médica: um relato de experiência 72

Título: O impacto do Tai Chi Chuan na Hipertensão Arterial Sistêmica Essencial: uma revisão narrativa

Título: Projeto "Acolhendo Quem Cuida": Oferta da terapia mesa radiônica via remota em tempos de pandemia.

Título: A utilização da acupuntura auricular no tratamento da dor lombar em gestantes de risco habitual......

Título: Eficácia da musicoterapia no tratamento do transtorno do espectro autista: uma revisão integrativa..

Título: Trabalho final da disciplina "Práticas Complementares em Saúde" no Ensino Remoto Emergencial: Relato de experiência..

Título: Níveis de evidências dos estudos científicos sobre Reiki no Brasil: uma revisão integrativa...

Título: O impacto da formação de uma Liga Acadêmica de Medicina Integrativa no desenvolvimento acadêmico de estudantes de Medicina. 
Título: Práticas integrativas e complementares em saúde: uma realidade no SUS. 88

Título: Sinais e sintomas de ansiedade em meio à pandemia: um relato de experiência sobre a aplicação de Reiki a distância como forma de redução do sofrimento 90

AGRADECIMENTOS 92 


\section{SOBRE O EVENTO}

É com entusiasmo que apresentamos o I Congresso Acadêmico de Práticas Integrativas e Complementares em Saúde (ConAPICS) Brasil 2020. O evento tem como objetivo difundir e discutir os conhecimentos acerca das Práticas Integrativas e Complementares em Saúde (PICS), correlacionando diversas áreas da saúde e profissionais, como também questionar e colocar em evidência a carência dos currículos acadêmicos no que diz respeito à PICS.

Este evento é fruto da parceria entre sete ligas acadêmicas de Práticas Integrativas e Complementares em Saúde e onze ligas de Medicina de Família e Comunidade e Medicina Integrativa entusiastas de PICS.

A Universidade Federal de São João Del-Rei Campus Centro Oeste - (UFSJ CCO) apoia o I ConAPICS Brasil 2020 e se coloca como Universidade do Congresso, estimulando sempre a interdisciplinaridade como principal ferramenta para melhores trocas de experiências.

O congresso ocorrerá nos dias 24, 25 e 26 de novembro de 2020, no período noturno das $19 \mathrm{~h}$ às $21 \mathrm{~h} 30$. 


\section{Organizadores do Evento}

\section{Direção Geral}

Diretor Geral Discente: William Bueno.

Vice-Diretor Geral Discente: Bruno Lima.

Diretor Docente: Lucas Gaspar Ribeiro.

\section{Comissão Científica}

Diretora Discente: Samara Gomes Rodrigues.

Vice-Diretor Discente: André Luis do Nascimento Ferreira.

Diretora Docente: Ms. Rosana Pires Russo Bianco.

Membros integrantes: Barbara Vitoria Claudino Martins, Camila Lopes de Oliveira, Giovana Caldas Pereira, Josiane de Lima Balbino dos Santos, Kawany de Oliveira Rodrigues, Larissa Campos da Silva e Thuany Montes de Almeida. 


\section{Programação}

\begin{tabular}{|c|c|c|}
\hline \multicolumn{3}{|c|}{24 de novembro } \\
\hline $19 \mathrm{~h} 00$ & $\begin{array}{l}\text { Abertura do Congresso: Apresentação das ligas participantes e Diretores } \\
\text { de Comissões. }\end{array}$ & $5 \mathrm{~min}$ \\
\hline 19h05 & Comissão Cultural apresenta obras finalistas & $15 \mathrm{~min}$ \\
\hline $19 \mathrm{~h} 20$ & Mesa Redonda 1 (Tema a definir) & $40 \mathrm{~min}$ \\
\hline $20 \mathrm{~h} 00$ & $\begin{array}{c}\text { Apresentação dos Patrocinadores e lançamento da primeira pergunta no } \\
\text { Instagram para sorteio. }\end{array}$ & $10 \mathrm{~min}$ \\
\hline $20 h 10$ & Palestra Principal + perguntas & $40 \mathrm{~min}$ \\
\hline $20 h 50$ & $\begin{array}{l}\text { Lançamento da segunda pergunta no Instagram para sorteio e } \\
\text { divulgação dos links das Salas Acadêmicas de Discussão. }\end{array}$ & $10 \mathrm{~min}$ \\
\hline $21 \mathrm{~h} 00$ & $\begin{array}{l}\text { Sala 1: Conexão William Bueno (MG), Victoria Amoedo (BA) e Livia } \\
\text { Schultz (ES): } \\
\text { Desafios e benéficos de uma LAPIC para a Universidade. } \\
\text { Sala 2: Conexão Izabella Lima (SP), Bruna Hellen (ES) e Jefferson } \\
\text { Souza (SE): Plantas medicinais - Fitoterapia } \\
\text { Sala 3: Conexão Marco Antonio (ES) e Marcela Oliveira } \\
\text { (MG): Terapia Comunitária }\end{array}$ & $30 \mathrm{~min}$ \\
\hline
\end{tabular}

\begin{tabular}{|c|c|c|}
\hline \multicolumn{3}{|c|}{25 de novembro } \\
\hline $19 \mathrm{~h} 00$ & Abertura e Avisos & $5 \mathrm{~min}$ \\
\hline $19 h 05$ & Comissão Cultural apresenta obras finalistas & $15 \mathrm{~min}$ \\
\hline $19 h 20$ & Mesa Redonda 2 (Tema a definir) & $40 \mathrm{~min}$ \\
\hline $20 \mathrm{~h} 00$ & $\begin{array}{l}\text { Apresentação dos Patrocinadores e lançamento da primeira pergunta no } \\
\text { Instagram para sorteio. }\end{array}$ & $10 \mathrm{~min}$ \\
\hline $20 h 10$ & Palestra Principal + perguntas & $40 \mathrm{~min}$ \\
\hline $20 h 50$ & $\begin{array}{l}\text { Lançamento da segunda pergunta no Instagram para sorteio e } \\
\text { divulgação dos links das Salas Acadêmicas de Discussão. }\end{array}$ & $10 \mathrm{~min}$ \\
\hline
\end{tabular}




\begin{tabular}{|l|c|c|}
\hline 21h00 & Sala 1: Conexão Janaína Gerosa (SP) e XX \\
Apiterapia & $30 \mathrm{~min}$ \\
& $\begin{array}{c}\text { Sala 2: Conexão Moises Fiusa (MG), Jhon Helbert (MT) e André } \\
\text { Ferreira (RJ) PICS e Pseudociência }\end{array}$ & \\
& $\begin{array}{c}\text { Sala 3: Conexão Liamara Lezan (Paraguai) e Bruno Lima (MG) } \\
\text { Reiki }\end{array}$ & \\
\hline
\end{tabular}

\begin{tabular}{|c|c|c|}
\hline \multicolumn{3}{|c|}{26 de novembro } \\
\hline $19 \mathrm{~h} 00$ & Abertura e Avisos & $5 \mathrm{~min}$ \\
\hline $19 h 05$ & Mesa Redonda 3 (Tema a definir) & 40min \\
\hline $19 h 45$ & $\begin{array}{l}\text { Apresentação dos Patrocinadores e lançamento da primeira pergunta no } \\
\text { Instagram para sorteio. }\end{array}$ & $10 \mathrm{~min}$ \\
\hline $19 h 55$ & Palestra Principal + perguntas & 40min \\
\hline $20 h 35$ & Lançamento da segunda pergunta no Instagram para sorteio. & $5 \mathrm{~min}$ \\
\hline $20 \mathrm{~h} 40$ & Comissão Cultural divulga as obras vencedoras. & $20 \mathrm{~min}$ \\
\hline $21 \mathrm{~h} 00$ & $\begin{array}{c}\text { Apresentação dos } 3 \text { trabalhos científicos finalistas em } 5 \text { min cada e logo } \\
\text { após Comissão Científica divulga a colocação dos } 3 \text { primeiros trabalhos e } \\
\text { finaliza o I ConAPICS Brasil } 2020 .\end{array}$ & $30 \mathrm{~min}$ \\
\hline
\end{tabular}




\section{APRESENTAÇÃO}

As Práticas Integrativas e Complementares em Saúde (PICS) têm ocupado um espaço de maior relevância na produção acadêmica da área. Todavia, os espaços destinados à publicação dessas pesquisas ainda não contemplam toda a demanda gerada, especialmente quando se trata daquela produção originada de acadêmicos. Neste sentido, - I ConAPICS cumpre o papel de abrir espaço para a exposição e discussão desses temas entre estudantes, pesquisadores e profissionais de todas as regiões do Brasil, oferecendo um grande e melhor conhecimento sobre as Práticas.

O I ConAPICS teve a honra de receber 110 resumos de trabalhos científicos que foram avaliados pela comissão, sob os seguintes critérios: a) pertinência ao tema do congresso; b) originalidade; c) atenção aos preceitos éticos, morais e científicos; d) coerência e coesão textual; e e) atenção às normas e orientações indicadas no edital e nos modelos disponibilizados. Foram aceitos trabalhos dos seguintes tipos: estudo original, revisão de literatura, estudo de caso e relato de experiência. Desse processo, emergiram 41 trabalhos aprovados que compõem estes anais, contribuindo para a divulgação das PICS no meio acadêmico. 


\section{Resumos Simples}

RESUMO SIMPLES: Revisão Bibliográfica

Título: A Mindfulness na prevenção de transtornos alimentares

Autor/coautores: Alana Gabriela Conceição Hora; Franciele Menezes Santana; Júlia Borges Giudice Monteiro; Marcela Torres da Silva, Tereza Raquel Ribeiro de Sena

Instituição: Universidade Federal de Sergipe (UFS), São Cristóvão-Sergipe.

Palavras-chave: Atenção Plena; Transtornos Alimentares; Prevenção.

\section{INTRODUÇÃO}

Transtornos alimentares são desordens nos hábitos alimentares que ocorrem principalmente em consequência de sentimentos negativos relacionados à autoimagem e à pressão estética. Estudos demonstram prejuízos na saúde mental e física, gerados tanto nos transtornos alimentares no nível de diagnóstico, como nos padrões associados a essas condições, revelando a importância de abordagens preventivas (LINARDON J, et al., 2019). Nesse sentido, a Mindfulness ou Atenção Plena, forma particular de direcionar a atenção para o momento presente, e sem julgamento (RAHAL GM, 2018), se apresenta como possibilidade ao auxiliar nos pensamentos de autoaceitação, consciência e calma, agindo nos fatores de risco para transtornos alimentares.

\section{OBJETIVO}

Revisar a literatura científica sobre as contribuições da Mindfulness para prevenção de Transtornos Alimentares, mediante desempenho dessa prática nos fatores de risco e possíveis sintomas associados às desordens em questão.

\section{MÉTODO}

Trata-se de revisão integrativa realizada nas bases de dados Cochrane, IBECS, LILACS e MEDLINE, utilizando os descritores "Feeding and Eating Disorders", "Mindfulness" e a combinação por operador booleano "AND". Foram selecionados 4 estudos, tendo como critérios de inclusão publicações dos últimos cinco anos, em português ou inglês, e de exclusão, artigos duplicados. A seleção dos estudos ocorreu mediante leitura do título, seguindo pelo resumo, e demais partes do texto.

\section{REVISÃO BIBLIOGRÁFICA}

A partir dos estudos selecionados, pôde-se observar que a Mindfulness, atua tanto no tratamento como na prevenção de transtornos alimentares, melhorando a autoaceitação e a relação dos indivíduos com seus 
pensamentos acerca do peso, aparência e alimentação (LINARDON J, et al., 2019). Pesquisa realizada com alunos, na adolescência, mostrou o papel decisivo desses pensamentos, considerados fatores de risco, no desenvolvimento ou não desses transtornos, e por isso é proveitosa a prática de Mindfulness, nessa fase para a prevenção de tais distúrbios (ATKINSON MJ e WADE TD, 2015). Estatisticamente, estudo com quarenta e quatro mulheres, apresentou que a atenção plena é benéfica no controle dos fatores de risco em um curto prazo, demandando assim uma melhor compressão, facilidade e a prática frequente dessa terapia para garantir seus efeitos benéficos a longo prazo (ATKINSON MJ e WADE TD, 2016).

\section{CONSIDERAÇÕES FINAIS}

A Mindfulness apresenta potencial na prevenção de transtornos alimentares por contribuir na melhoria dos fatores de risco associados. Entretanto, mais estudos precisam ser realizados para superar as limitações decorrentes da durabilidade do efeito da prática, a efetividade em públicos distintos, a aceitabilidade e reprodutibilidade das estratégias utilizadas.

\section{REFERÊNCIAS}

1. ATKINSON MJ, WADE TD. Mindfulness-based prevention for eating disorders: A school-based cluster randomized controlled study. International Journal of Eating Disorders, 2015; 48(7), 1024-1037.

2. ATKINSON MJ, WADE TD. Does mindfulness have potential in eating disorders prevention? A preliminary controlled trial with young adult women. Early Intervention in Psychiatry, 2016; 10(3), 234245.

3. LINARDON J, et al. Meta-analysis of the effects of third-wave behavioural interventions on disordered eating and body image concerns: implications for eating disorder prevention. Cognitive Behaviour Therapy, 2019; 48(1), 15-38.

4. RAHAL GM. Mindfulness in the school context: Benefits and possibilities of integration. Psicologia Escolar e Educacional, 2018; 22(2), 347-358. 
RESUMO SIMPLES: Relato de Experiência

Título: A Prática de Yoga durante a Pandemia: Relato de experiência

Autor/coautores: Marcela Torres da Silva'; Maria Rafaella Carvalho de Jesus'; Brunna Santos de Oliveira'; Patrícia Souza Fortuna².

Instituição: 'Universidade Federal de Sergipe (UFS), São Cristóvão-Sergipe; ${ }^{2}$ Universidade do Estado da Bahia (UNEB), Salvador-Bahia

Palavras-chave: Yoga, Pandemia, Práticas Integrativas.

\section{INTRODUÇÃO}

O Yoga é uma prática holística que inclui não apenas a execução de posturas corporais, mas também da conexão entre corpo, mente e espírito (ROSA AL e MIRANDA AVS, 2017). Como técnica terapêutica, o Yoga apresenta vários benefícios para a saúde do corpo físico e aos transtornos mentais, tais como redução da ansiedade e do estresse (MEDEIROS AM, 2017). Assim, diante da pandemia e isolamento social, os impactos psicológicos podem ser imensuráveis, ao comparar com epidemias passadas. Com isso, de acordo com o estudo analisado, a prática regular do Yoga contribuiu para o controle de saúde física e mental dos participantes (CORREA CA, et al., 2020).

\section{OBJETIVO}

Relatar a experiência da prática regular de yoga durante o isolamento social da pandemia do novo coronavírus (COVID-19), assim como as suas contribuições para o bem-estar físico, mental e emocional dos participantes.

\section{RELATO DE EXPERIÊNCIA}

Com o início do isolamento social ocasionado pela pandemia do novo coronavírus (COVID-19), as aulas de yoga, anteriormente feitas de modo presencial, precisaram se adequar ao novo contexto e migrar para a plataforma online. A prática, que combina posturas físicas, respiração e meditação, é recomendada para a manutenção da saúde física, mental e emocional. As aulas realizadas remotamente, praticadas três vezes por semana, proporcionaram a redução de dores de coluna, aumento da percepção corporal, alívio de estresse, melhora da disposição, equilíbrio emocional e momentos de autocuidado, além de possibilitar o contato com outras pessoas, mesmo que de forma virtual. Com isso, as alterações no estilo de vida causadas pelo COVID-19, e principalmente a preocupação quanto a infecção e transmissão do vírus, puderam ser amenizadas a partir do cuidado corporal e mental com o auxílio do yoga.

Durante a flexibilização do isolamento social, com a autorização da retomada das atividades presenciais do yoga, o impacto se deu principalmente em realizar a prática com máscara facial, ocasionando incômodos. Apesar disso, os benefícios relatados anteriormente permaneceram.

\section{CONSIDERAÇÕES FINAIS}

A partir do experienciado, a prática de yoga é uma ótima alternativa para o enfrentamento de situações de estresse e ansiedade, intensificadas durante o período de isolamento social. É uma prática que combina o 
cuidado com a saúde física e a saúde mental, sendo de suma importância sua inserção no cotidiano como forma de autocuidado.

\section{REFERÊNCIAS}

1. CORREA CA, et al. Níveis de estresse, ansiedade, depressão e fatores associados durante a pandemia de COVID-19 em praticantes de Yoga. Revista Brasileira de Atividade Física \& Saúde, 2020; 25: e0118.

2. MEDEIROS AM. Práticas integrativas e complementares no SUS: os benefícios do Yoga e da Meditação para a saúde do corpo e da alma. Revista Eletrônica Correlatio, 2017; 16(2): 284-301.

3. ROSA AL, MIRANDA AVS. O Yoga como prática integrativa na promoção de saúde mental: Uma ferramenta ética para o cuidado de si. Revista Rizoma: experiências interdisciplinares em ciências humanas e ciências sociais aplicadas, 2017; 1(2): 178-190. 
RESUMO SIMPLES: Relato de Experiência

Título: Disciplina Felicidade, a inclusão de Práticas Integrativas e Complementares na Universidade

Autor/coautores: Maria Eduarda Figueiredo Santos, Cláudia Maria de Souza Gonçalves, Larissa de Freitas Vilela, Moisés Fiúsa Menezes, William Alves Bueno.

Instituição: Universidade Federal de São João del-Rei (UFSJ), Divinópolis-Minas Gerais.

Palavras-chave: Ansiedade, Bem-estar, Felicidade.

\section{INTRODUÇÃO}

O ensino da Felicidade, baseado na psicologia positiva, originou-se na Universidade de Harvard, e desde 2018 é introduzido nos cursos superiores do Brasil (GONÇALVES JAT, 2019). A disciplina é decorrente da crescente taxa de fatores ansiogênicos, depressivos e exaustivos encontrado nos discentes (FERNANDES MA, et al., 2018). Nesse sentido as Universidades, como centros de integração não apenas profissional, mas social, devem promover o bem-estar e o autoconhecimento aos estudantes (FERREIRA FMPB, et al., 2018). [A1] A introdução de Práticas Integrativas e Complementares em Saúde (PICS), na disciplina, incorpora ensinamentos e técnicas em benefício a diminuir a ansiedade e aumentar a felicidade subjetiva (BREEDVELT JJF, et al., 2019).

\section{OBJETIVO}

Apresentar a dinâmica da disciplina Felicidade com a inclusão das PICS lecionada nos cursos superiores de uma universidade pública mineira onde a unidade curricular foi introduzida no ano de 2019.

\section{RELATO DE EXPERIÊNCIA}

A unidade curricular Felicidade passou a ser ofertada no campus de uma universidade pública mineira que congrega os cursos de Bioquímica, Enfermagem, Farmácia e Medicina, no ano de 2019. A disciplina é organizada por docentes especialistas na área da saúde e tem como público alvo os estudantes. Dividida em doze conteúdos programáticos, possui como fundamentação teórica o livro "O jeito Harvard de ser feliz" de Shawn Achor, que varia entre regra dos 20 segundos, efeito tetris e propagador.

Os professores responsáveis incluíram PICS em dinâmicas de grupo e exercícios individuais, como meditação, terapia comunitária e análise bioenergética. A meditação é empregada de forma pessoal, onde os docentes explicam sua técnica e importância, com finalidade do aluno conseguir aumentar sua concentração e aprimorar o autoconhecimento. A terapia comunitária é efetuada com todos os discentes e é realizada de modo descontraído, em um espaço aberto para se expressarem e criarem laços de apoio social e emocional. A análise bioenergética ocorre em coletivo por movimentos corporais associados à respiração, e tende a diminuir os níveis de estresse, ansiedade e angústia.

\section{CONSIDERAÇÕES FINAIS}

A inclusão das PICS no ensino da Felicidade tem se mostrado fundamental, visto que assuntos que abordam não só o corpo, mas também a mente, são associados ao autoconhecimento, equilíbrio e harmonia, bases dessas práticas. Assim, o estudo das PICS em junção com a disciplina Felicidade tem apresentado 
resultados admiráveis em relação à saúde mental dos estudantes, expandindo a capacidade de autoconhecimento, promovendo um melhor ambiente acadêmico.

\section{REFERÊNCIAS}

1. BREEDVELT JJF, et al. The effects of meditation, yoga and mindfulness on depression, anxiety, and stress in tertiary education students: A meta-analysis. Front Psychiatry, 2019; 10(1): e10.3389.

2. FERNANDES MA, et al. Prevalence of anxious and depressive symptoms in college students of a public institution. Revista Brasileira de Enfermagem, 2018; 71(5): e10.1590.

3. FERREIRA FMPB, et al. Health promotion programs in higher education: integrative review of the literature. Revista Brasileira de Enfermagem, 2018; 71(4): e1714-23.

4. GONÇALVES JAT. Ensinando 'Felicidade': Aprendizagem socioemocional no ensino superior. Revista Eletrônica Toledo Prudente,2019; 15(15): e21-76-8498. 
RESUMO SIMPLES: Revisão Bibliográfica

Título: Ozonioterapia como adjuvante ao manejo da fibromialgia: uma revisão integrativa

Autor/coautores: Thiago Vinícius Gomes de Oliveira'; Lucas Emanuel Carvalho Cavalcante1; Leonardo Vinícius de Brito Oliveira'; Sérgio Guilherme de Pina Dias ${ }^{1}$; Amanda de Figueirôa Silva²

Instituição: Universidade Federal de Pernambuco (UFPE) Caruaru-Pernambuco'; docente da Universidade Federal de Pernambuco (UFPE) Caruaru-Pernambuco ${ }^{2}$

Palavras-Chave: Ozonoterapia; Fibromialgia; Terapêutica.

\section{INTRODUÇÃO}

Apesar de ainda não consolidada no Brasil, a ozonioterapia tem se difundido como prática integrativa em diversos países e associada a um conjunto de propriedades como a capacidade anti-inflamatória, antisséptica, antioxidante ou mesmo a otimização da hemodinâmica e da oxigenação (ORNELAS PTSF, et al., 2020). A partir de sua potencial propriedade de regulação positiva do sistema antioxidante, foi firmada a hipótese de que a ozonioterapia teria potencial de alívio dos sintomas da fibromialgia, o que tem sido discutido e utilizado de forma experimental na literatura científica no decorrer dos últimos anos (SEYAM O, et al., 2018; SOLER MO, et al., 2016).

\section{OBJETIVO}

Revisar a literatura científica em busca de unir informações acerca do que se têm de mais recente sobre a utilização da ozonioterapia como possível adjuvante na abordagem terapêutica da fibromialgia.

\section{MÉTODO}

Revisão integrativa da literatura sobre Ozonioterapia no manejo da Fibromialgia. Plataformas utilizadas: PubMed e Scopus. Pesquisa por "(Ozone) AND (Fibromyalgia): 25 artigos encontrados. Critério de inclusão: restrição aos artigos publicados nos últimos 5 anos. Critérios de exclusão: duplicidade e não associação a temática. Um total de 5 artigos foram considerados elegíveis.

\section{REVISÃO BIBLIOGRÁFICA}

Estudos demonstram, com poucas semanas de tratamento com o ozônio, diminuição considerável de biomarcadores do estresse oxidativo, redução de espécies reativas de oxigênio e elevação dos índices de serotonina em comparação com a avaliação prévia ao tratamento dos pacientes (BARANOVA IV, et al., 2020). Em estudos clínicos, a ozonioterapia tem sido associada a uma redução dos tender points, da fraqueza muscular, fadiga, distúrbios do sono e da frequência e intensidade da cefaleia; refletindo em uma melhora concreta na qualidade de vida, comprovada por melhores resultados em escalas de avaliação do impacto da fibromialgia, na escala de avaliação numérica da dor e escala de severidade de fadiga em grande parte dos pacientes avaliados (MORENO-FERNÁNDEZ AM, et al., 2019; TIRELLI U, et al., 2019). Outro importante aspecto é o relato de ausência de efeitos colaterais consideráveis ou de alterações significativas nos padrões bioquímicos, oportunizando para além da possível efetividade a segurança na realização de tal abordagem (TIRELLI U, et al., 2019). 


\section{CONSIDERAÇÕES FINAIS}

A ozonioterapia tende a ser uma abordagem efetiva no tratamento da fibromialgia. No entanto, apesar de resultados promissores, ainda existem poucos estudos clínicos que a consolide como adjuvante na terapêutica da doença, sendo necessária uma maior análise científica com relação a tal prática, garantindo uma melhor avaliação de sua efetividade.

\section{REFERÊNCIAS}

1. BARANOVA IV, et al. Analgetic effect of ozone therapy: myths of reality?, Polish Annals of Medicine, 2020; 27(1): 62-67.

2. MORENO-FERNÁNDEZ AM, et al. Autohemotherapy with ozone as a possible effective treatment for Fibromyalgia. Acta Reumatologica Portuguesa, 2019; 44(3): 244-249.

3. ORNELAS PTSF, et al. As evidências científicas da eficácia do uso da ozonioterapia frente à legislação sanitária brasileira. Revista de Divulgação Científica Sena Aires, 2020; 9(2): 320-326.

4. SEYAM O, et al. Clinical utility of ozone therapy for musculoskeletal disorders. Medical gas research, 2018; 8(3): 103.SOLER MO, et al. Ozonoterapia en el tratamiento de la fibromialgia. Dolor. Investigación Clínica \& Terapéutica, 2016; 31(4): 149-155.

5. TIRELLI U, et al. Ozone therapy in 65 patients with fibromyalgia: an effective therapy. Eur Rev Med Pharmacol Sci, 2019; 23(4): 1786-1788. 
RESUMO SIMPLES: Revisão Bibliográfica

Título: Benefícios das Práticas Integrativas e Complementares no controle da dor em pacientes crônicos

Autor/coautores: Maria Olívia de Araújo Pereira1', Lucas Thadeu Silva de Ferreira Morais², Marcela Regina Azevedo de Castro Oliveira', Maria Eduarda Figueiredo Santos', William Alves Bueno'1.

Instituição: Universidade Federal de São João del-Rei (UFSJ), Divinópolis-Minas Gerais'; Faculdade Pitágoras, Divinópolis-Minas Gerais².

Palavras-Chave: Práticas Integrativas; Dor Crônica; Tratamentos Alternativos.

\section{INTRODUÇÃO}

A dor integrada com variáveis fisiológicas, psicossociais e espirituais permitem reconhecer sua natureza multidimensional (RAJA SN, et al., 2020). Apesar dos avanços científicos no tratamento das doenças crônicas, ainda há limitações e consequências no uso dos anti-inflamatórios não esteroides (AINEs) (RADI ZA E KHAN $\mathrm{KN}, 2019$ ). Para alguns indivíduos a dor permanece sem perspectiva de cura. As Práticas Integrativas e Complementares em Saúde (PICS) ampliam o cuidado com ferramentas capazes de ativar forças curativas do organismo. As PICS são alternativas terapêuticas eficazes, mesmo quando a medicina ocidental encontra obstáculos no controle da dor.

\section{OBJETIVO}

Revisar literatura científica sobre os efeitos adversos do uso contínuo e indiscriminado de AINEs e a importância das PICS como alternativa terapêutica ao manejo da dor em portadores de doenças crônicas.

\section{MÉTODO}

Revisão integrativa de literatura com abordagem qualitativa. Utilizou-se as bases de dados BVS e PUBMED com os descritores: Dor Crônica AND AINES, Dor Crônica AND Terapias alternativas. A análise inclui artigos de pesquisa, estudos de caso e teses em inglês ou português publicados entre 2015 a 2020. Critérios de exclusão definidos: artigos sem acesso ao texto integral; artigos de revisão de literatura; cartas e editoriais

\section{REVISÃO BIBLIOGRÁFICA}

Dentre as 19000 publicações encontradas sobre o tema, 5 estudos foram avaliados e incluídos na análise. Os AINEs são fármacos prescritos no controle das dores agudas e crônicas, sendo seu uso prolongado nocivo à saúde renal, gastrointestinal e circulatória. (RADI ZA E KHAN KN, 2019). As PICS mostram-se tratamentos complementares aos demais por serem comprovadamente eficazes e de custo acessível para a população. Compreendendo o indivíduo como um todo, apresentam uma visão multidimensional do processo saúdedoença focado no empoderamento individual. Possuem habilidades de estimulação natural dos mecanismos do organismo humano como redução de células inflamatórias (BOWER JE E IRWIN MR, 2016) e manutenção de importantes peptídeos antimicrobianos (TWAL W, et al., 2016). Estudos sugerem benefícios em relação ao uso das PICS como redução de medicação, empoderamento do autocuidado e diminuição de transtornos mentais comuns (NASCIMENTO MVN e OLIVEIRA IF, 2016). 


\section{CONSIDERAÇÕES FINAIS}

Visando reduzir o uso indiscriminado de AINEs no controle da dor, as PICS ampliam o cuidado promovendo saúde mental e física. Os potenciais terapêuticos advindos da Medicina Tradicional Chinesa apontam melhoria no quadro clínico e efetividade do cuidado, possibilitando qualidade de vida aos portadores de doenças crônicas. Importante enfatizar a necessidade de mais estudos para expandir as evidências sobre a eficácia científica das PICS.

\section{REFERÊNCIAS}

1. RAJA SN, et al. Definição revisada de dor pela Associação Internacional para o Estudo da Dor: conceitos, desafios e compromissos. Jornal Dor, 2020; 74: 11-8.

2. RADI ZA, KHAN KN. Cardio-renal safety of non-steroidal anti-inflammatory drugs. The Journal of toxicological sciences. 2019; 44(6): 373-391.

3. BOWER JE, IRWIN MR. Mind-body therapies and control of inflammatory biology: A descriptive review. Brain, behavior, and immunity, 2016; 51: 1-11.

4. TWAL WO, et al. Yogic breathing when compared to attention control reduces the levels of proinflammatory biomarkers in saliva: a pilot randomized controlled trial. BMC complementary and alternative medicine, 2016; 16, 294: e27538513.

5. NASCIMENTO MVN, OLIVEIRA IF. As práticas integrativas e complementares grupais e sua inserção nos serviços de saúde da atenção básica. Estudos de Psicologia (Natal), 2016; 21(3): 272-281. 
RESUMO SIMPLES: Relato de Experiência

Título: Experiências de estudantes de medicina acerca do ensino das práticas integrativas e complementares aplicando as metodologias ativas

Autor/coautores: Daniel Bastos Alves Lima, Ângela Reis Teixeira, Thanilly Silveira Macedo, Júlio Samuel Silva Souza, Patrícia Baier Krepsky.

Instituição: Universidade Federal da Bahia (UFBA), Vitória da Conquista-Bahia.

Palavras-chave: Práticas integrativas e complementares, Saúde pública, Ensino superior.

\section{INTRODUÇÃO}

As Práticas Integrativas e Complementares (PICS) foram institucionalizadas nacionalmente no sistema único de saúde (SUS) em 2006, a partir da aprovação de sua política nacional, com intuito de fortalecer o cuidado integral à população brasileira (RUELA LO, et al., 2018). Desde as novas diretrizes curriculares nacionais para o curso de medicina, e da necessidade de novas ferramentas de ensino, as metodologias ativas surgem promovendo o protagonismo do estudante e quebrando a lógica vertical dos processos de ensino-aprendizagem (COLARES KTP e OLIVEIRA W, 2019). Ademais, os cursos de medicina passaram a promover a valorização do SUS nas matrizes curriculares, propiciando conhecimentos essenciais à formação (FERREIRA MJM, et al., 2019).

\section{OBJETIVO}

Relatar a experiência de discentes de medicina em uma Universidade Federal do Sudoeste Baiano, no componente curricular intitulado "Práticas Integrativas e Complementares do SUS", evidenciando os benefícios das metodologias ativas no seu processo ensino-aprendizagem.

\section{RELATO DE EXPERIÊNCIA}

O componente curricular foi ofertado no primeiro semestre da graduação, favorecendo o contato inicial com as PICS, sendo dividido em três módulos de natureza obrigatória. Dois docentes ministraram as aulas, uma farmacêutica e um antropólogo, permitindo visão multidisciplinar sobre seus aspectos. No primeiro módulo, tivemos aulas teóricas e, com auxílio das metodologias ativas, levantaram-se debates calorosos e desafiadores, estimulando a construção coletiva do conhecimento sobre as PICS.

No segundo módulo, os professores selecionaram profissionais que são referência e que atuam nas diversas áreas das PICS para proferirem palestras sobre seu processo de trabalho, além da realização de vivências coletivas quando possível, permitindo contato precoce com tais práticas. Dentre os temas trabalhados podemos destacar a medicina tradicional chinesa, terapia comunitária integrativa, meditação, homeopatia, dentre outras. O terceiro módulo foi composto por atividades em laboratório de informática, dando enfoque à pesquisa científica sobre fitoterápicos, mostrando que algumas PICS possuem comprovação científica robusta, além de inserir os discentes no universo da pesquisa. Experiências como essas corroboram para formação médica dinâmica e ampliada, favorecendo posteriormente $\mathrm{o}$ atendimento integral e fortalecimento do SUS. 


\section{CONSIDERAÇÕES FINAIS}

A trajetória pelo componente curricular proporcionou experiências enriquecedoras e essenciais na construção de conhecimentos sobre as PICS. A utilização das metodologias ativas levou a inserção dos discentes nas práticas de saúde, seja através das discussões, contato com profissionais atuantes ou das vivências, reconhecendo o impacto positivo das práticas integrativas e complementares na saúde pública, bem como a importância da valorização e ampliação dessas práticas de cuidado.

\section{REFERÊNCIAS}

1. RUELA LO, et al. Implementação, acesso e uso das práticas integrativas e complementares no sistema único de saúde: Revisão da literatura. Ciência \& Saúde Coletiva, 2019; 24; 4239-4250.

2. COLARES KTP, DE OLIVEIRA W. Metodologias Ativas na formação profissional em saúde: uma revisão. Revista Sustinere, 2018; 6(2); 300-320.

3. FERREIRA MJM, et al. Novas Diretrizes Curriculares Nacionais para os cursos de Medicina: oportunidades para ressignificar a formação. Interface-Comunicação, Saúde, Educação, 2019; 23: e170920. 
RESUMO SIMPLES: Revisão Bibliográfica

Título: Efeito do Silexan sobre o sono: uma revisão bibliográfica

Autor/coautores: Luísa Granzinolli Mattos, Camila dos Reis Neves, Anna Laura Lima Delphino, Jamille Gadbem Rosa, Leopoldina Leonor Fagundes.

Instituição: Faculdade de Ciências Médicas da Saúde de Juiz de Fora (Suprema), Juiz de Fora- Minas Gerais

Palavras-Chave: Óleo Essências; Lavanda; Sono.

\section{INTRODUÇÃO}

O sono é de fundamental importância porque é uma necessidade vital para o controle fisiológico e psicológico dos indivíduos. Contudo, esse sono pode ficar conturbado devido a vários fatores como ansiedade, fatores ligados a doenças crônicas e internações (KARADAG E, et al., 2015). Sendo assim, o uso de medicamento fitoterápicos tem sido uma abordagem interessante na melhoria da qualidade do sono. Para isso, tem sido usado o silexan que é um óleo essencial oriundo da lavanda (SEIFRITZ E, et al., 2019), devido as propriedades ansiolíticas que esse óleo tem (KASPER S, et al.,2016).

\section{OBJETIVO}

Analisar, por meio da literatura científica a eficácia do silexan como estratégia no tratamento da melhoria do sono em pacientes que apresentam algum problema relacionado a uma boa qualidade de sono.

\section{MÉTODO}

Está revisão integrativa analisou estudos publicados na base de dados MedLine, utilizando os descritores essential oil; lavender; sleep e suas variações obtidas através do MeSH. Foram incluídos ensaios clínicos controlados e randomizados (ECCRs), realizados em humanos, em inglês e publicado nos últimos 5 anos seguindo os critérios do Índice de Qualidade do Sono de Pittsburgh (PSQI). Foram excluídos estudos não relacionados diretamente com o objetivo dessa revisão.

\section{REVISÃO BIBLIOGRÁFICA}

Os três ECCRs selecionados envolveram juntos 442 pacientes que apresentavam distúrbios do sono, fazendo uso do silexan entre 10 a 15 semanas. Os resultados demonstram que o uso de silexan foi bem tolerado por todos os pacientes e resultou na melhoria da qualidade do sono quando comparado ao grupo que não fez uso. (KARADAG E, et al., 2015; SEIFRITZ E. et al., 2019; KASPER S, et al., 2016).

A intervenção com uso do fitoterápico apresentou diferenças significativa a favor do uso, devido a melhora dos resultados do índice PSQI dos pacientes, após o uso do Silexan durante o tempo previsto pelos estudos. (KARADAG E, et al., 2015; SEIFRITZ E. et al., 2019; KASPER S, et al., 2016).

Essa eficácia é devido ao Silexan agir inibindo canais de cálcio dependente de voltagem levando a redução da resposta inadequada do sistema nervoso central agindo, desse modo, como ansiolítico. 
Ademais, ele age também inibindo o 5-HT 1A aumentando a serotonina extracelular (SEIFRITZ E, et al., 2019).

\section{CONSIDERAÇÕES FINAIS}

A administração do Silexan na dosagem de $80 \mathrm{mg} /$ dia ou inalação do óleo de lavanda $2 \% 5$ gotas/dia apresentou eficácia terapêutica na melhoria da qualidade do sono de pacientes que apresentavam alguma perturbação sendo uma medida barata e eficaz de tratamento.

\section{REFERÊNCIAS}

1. KARADAG E, et al. Efeitos da aromoterapia na qualidade do sono e ansiedade dos pacientes. Associaçao Britanica de Enfermeiros de Cuidados Críticos, 2017; 22(2): 105-112.

2. KASPER S, et al. Eficacia do Silexan administrado por via oral em pacientes com inquietação relacionada à ansiedade e distúrbios do sono - Um estudo randomizado controlado por placebo. European jornal neuroradiology cho pharmacol, 2015; 25(11): 1960-7

3. SEIFRITZ E, et al. Os efeitos benéficos do Silexan no sono são mediados por seu efeito ansiolítico. J Psychiatr Res, 2019; 115: 69-74. 
RESUMO SIMPLES: Revisão Bibliográfica

Título: Aromaterapia no tratamento da Dismenorreia Primária: uma revisão sistemática

Autor/coautores: Nara Assis Salgarello', Isadora Estefânio Coelho', Nathália dos Santos Couto¹, Victor Rocha Moreira Antunes ${ }^{1}$, Leopoldina Leonor Fagundes ${ }^{1}$

Instituição: 'Faculdade de Ciências Médicas e da Saúde de Juiz de Fora - SUPREMA, Juiz de Fora- Minas Gerais

Palavras-Chave: Aromaterapia; Dismenorreia; Tratamento.

\section{INTRODUÇÃO}

A Dismenorreia Primária (DP) é uma desordem que acomete diversas mulheres, principalmente adolescentes, no período antes ou durante sangramento menstrual. Está associada à dor na região inguinal e costas, além de cólicas abdominais, náuseas, vômitos e cefaleia. A aromaterapia é o uso terapêutico de óleos essenciais, os quais são derivados do metabolismo especial das plantas, capazes de atuar na redução de dor e estresse, bem como no aumento da sensação de bem-estar. Há muitos estudos que propõem investigação a respeito da eficácia da aromaterapia no tratamento da DP (APAY SE, et al., 2015).

\section{OBJETIVO}

Investigar, por meio de uma revisão sistemática na literatura, quais são os efeitos da prática da aromaterapia no tratamento e alívio dos sintomas da DP, assim como a sua eficácia.

\section{MÉTODO}

Foram analisados ensaios clínicos controlados e randomizados, originalmente em inglês, dos últimos dez anos, em humanos, através de revisão sistemática na base de dados National Library of Medicine (MEDLINE). Foi feita consulta ao MeSH com os descritores: Aromatherapy, Dysmenorrhea, Treatment e Effects. Foram excluídos estudos que não se encaixavam na discussão proposta. A escala PRISMA foi utilizada para melhorar o relato desta revisão (MOHER D, et al., 2009).

\section{REVISÃO BIBLIOGRÁFICA}

Dentre os oito estudos que inicialmente foram selecionados, cinco deles foram utilizados para compor o escopo dessa revisão. Os critérios de inclusão aplicados contemplaram estudos que avaliavam a eficácia da aromaterapia no tratamento da DP. Foram eliminados, pelos critérios de exclusão, estudos que apresentavam métodos pouco claros, mal descritos ou estudos sem ligação direta com a pesquisa que foi conduzida. Os estudos analisados compreenderam ao todo 757 mulheres, com idade mínima de 18 anos e residentes exclusivamente na Ásia. Em todos os estudos foi observado alívio dos sintomas. Em quatro deles, a sintomatologia da dismenorreia foi significativamente reduzida em pacientes submetidos à inalação e/ou massagem realizadas com óleos essenciais, quando comparados aos pacientes dos grupos controle, de acordo com medição em escala visual analógica (APAY SE, et al., 2015), (DEHKORDI ZR, et al., 2017), (SHAHR HAS, et al. 2015), (UYSAL M, et al., 2016). Em um dos estudos, a diminuição da duração da dor também foi constatada, porém com a utilização de escala verbal (OU MC, et al., 2015). 


\section{CONSIDERAÇÕES FINAIS}

Os estudos analisados sugerem efetividade da aromaterapia na redução da dor em indivíduos com DP, servindo como referência não farmacológica, de baixo custo e sem efeitos colaterais no tratamento dos pacientes. Entretanto, novas investigações devem ser realizadas considerando outras populações, visto que os resultados apresentados foram derivados de uma população exclusivamente oriental.

\section{REFERÊNCIAS}

1. APAY SE, et al. Effect of aromatherapy massage on dysmenorrhea in turkish students. Pain management nursing, 2015; 13: 236-40.

2. DEHKORDI ZR, et al. Effect of lavender inhalation on the symptoms of primary dysmenorrhea and the amount of menstrual bleeding: A randomized clinical trial. Conplementary Therapies in Medicine, 2017; 22: 212-9.

3. MOHER D, et al. Preferred Reporting Items for Systematic Reviews and Meta-Analyses: The PRISMA Statement. PLoS Med, 2009; 6(7): e1000097.

4. OU MC, et al. Pain relief assessment by aromatic essential oil massage on outpatients with primary dysmenorrhea: A randomized, dubble-blind clinical trial. J Obstet Gynaecol Res, 2015; 38(5): 817-22.

5. SHAHR HSA, et al. The effect of self-aromatherapy massage of the abdomen on the primary dysmenorrhoea. Journal of Obstetrics and Gynaecology, 2015; 35(4): 382-5.

6. UYSAL M, et al. Investigating the effect of rose essential oil in patients with primary dysmenorrhea. Complementary Therapies in Clinical Practice, 2016; 24: 45-9. 
RESUMO SIMPLES: Estudo Original

Título: Práticas Integrativas e Complementares: Conhecimento, utilização e eficácia dos acadêmicos na saúde

Autor/coautores: Dênia Vargas Vieira, ${ }^{1,2}$, Samara Maria Neves Barbosa ${ }^{1,2}$, Débora Fernandes de Melo Vitorino $^{1,2}$, Henrique Silveira Costa ${ }^{1,2}$, Fábio Luiz Mendonça Martins ${ }^{1,2}$.

Instituição: ${ }^{1}$ Universidade Federal dos vales do Jequitinhonha e Mucuri (UFVJM), Diamantina-Minas Gerais. 2 Programa de Pós-Graduação Residência em Fisioterapia na Saúde Coletiva (REFISC), Diamantina-Minas Gerais.

Financiamento: Ministério da Educação (MEC).

Palavras-chave: Política Nacional de Práticas Integrativas e Complementares. Medicinas Tradicionais Complementares e Integrativas. Universidades.

\section{INTRODUÇÃO}

As Práticas Integrativas e Complementares em Saúde (PICS) foram institucionalizadas no Sistema Único de Saúde (SUS) em 2006 através da Política Nacional de Práticas Integrativas e Complementares (PNPIC). As PICS contribuem para a ampliação das ofertas de cuidados em saúde, para a racionalização das ações de saúde, estimulando alternativas inovadoras e socialmente contributivas ao desenvolvimento sustentável de comunidades (BRASIL, 2015). O uso das PICS no SUS vem crescendo a cada ano (BRASIL, 2019), com isso, o Brasil tem se tornado pioneiro na oferta dessa modalidade na atenção básica (BRASIL, 2018). Entretanto, a formação profissional tem sido um dos maiores desafios para o seu avanço no SUS.

\section{OBJETIVO}

Mapear nos cursos da saúde de uma universidade federal na região do Vale do Jequitinhonha e Mucuri, o conhecimento dos acadêmicos do último ano sobre a existência, utilização e eficácia das Práticas Integrativas e complementares da Saúde (PICS)

\section{MÉTODO}

A amostra foi composta por 44 discentes (24 \pm 2 anos) do sexo feminino (80\%). Foi aplicado um questionário sobre o conhecimento e/ou vivência do discente sobre a existência das PICS e sua opinião quanto à inserção dessas práticas nos cursos de graduação. Realizou-se análise descritiva dos dados e o teste de Fisher no Excel/2016. Aprovado pelo Comitê de Ética em Pesquisa (CEP) sob CAAE n. 23949319.4.0000.5108.

\section{RESULTADOS}

Os resultados preliminares desde estudo demonstram que $90 \%$ dos discentes dos cursos da saúde da universidade pesquisada conhecem as práticas integrativas, $90 \%$ destes as consideram eficientes e $84 \%$ relatam acreditar na eficiência das práticas que conhecem. Das PICS mais desacreditas pelos discentes se encontra a Aromaterapia com apenas $7 \%$. Apenas $25 \%$ dos entrevistados demonstraram conhecer a Política Nacional de Práticas Integrativas e Complementares (PNPIC). A maioria dos discentes, 97\%, acreditam que as práticas podem contribuir para sua vida profissional e $91 \%$ acreditam que essas são capazes de contribuir para a Atenção em Saúde no SUS. 


\section{CONSIDERAÇÕES FINAIS}

Conclui-se que os acadêmicos possuem elevados índices de conhecimento sobre a existência das PICS, além de acreditarem e as considerarem eficientes. Embora poucos discentes conheçam a PNPIC, a maioria acredita que as práticas podem contribuir para a sua vida profissional e para Atenção em Saúde no SUS. Apesar disso, as PICS precisam ser institucionalizadas de forma mais eficiente permitindo que seus benefícios e aplicabilidade sejam cada vez mais difundidos.

\section{REFERÊNCIAS}

1. BRASIL. Ministério da Saúde. 2019. Cresce $46 \%$ procura por Práticas Integrativas Complementares no Sus. Disponível em: http://portalms.saude.gov.br/noticias/agenciasaude/45294-cresce-46-procura-porpráticas-integrativas-no-sus-2/. Acessado em: 10 de janeiro de 2020.

2. BRASIL. Ministério da Saúde. 2015. Secretaria de Atenção à Saúde. Departamento de Atenção Básica. Política nacional de práticas integrativas e complementares no SUS: atitude de ampliação de acesso. Disponível em: http://bvsms.saude.gov.br/pnpic. Acessado em: 2 de fevereiro de 2020.

3. BRASIL. Ministério da Saúde (2018). Secretaria de Atenção à Saúde. Departamento de Atenção Básica. Ministério da Saúde inclui 10 novas práticas integrativas no SUS. Disponível em: http://portalms.saude.gov.br/noticias/agencia-saude/42737-ministerio-da-saude-inclui-10-novaspraticas-integrativas-no-sus. Acessado em: 27 de março de 2019. 
RESUMO SIMPLES: Revisão Bibliográfica

Título: Uso da Valeriana officinalis para tratamento de distúrbios do sono: revisão integrativa

Autor/coautores: Sérgio Guilherme de Pina Dias"; Lucas Emanuel Carvalho Cavalcante'; Leonardo Vinícius de Brito Oliveira'; Thiago Vinícius Gomes de Oliveira'; Amanda de Figueirôa Silva².

Instituição: ${ }^{1}$ Discente da Universidade Federal de Pernambuco (UFPE) Caruaru-Pernambuco; ${ }^{2}$ Docente da Universidade Federal de Pernambuco (UFPE) Caruaru-Pernambuco.

Financiamento: Declaramos não ter recebido nenhum tipo de financiamento para a realização dessa pesquisa.

Palavras-chave: Valeriana Officinalis; Sono; Distúrbios do sono.

\section{INTRODUÇÃO}

A valeriana é extraída da Valeriana officinalis (V. wallichi/ edulis) e é produzida em forma de tintura, extrato padronizado e raiz seca para infusão ou comprimidos (SYS J, et al., 2020). Seu princípio ativo atua na recaptação do ácido gama-aminobutírico e provavelmente no agonismo parcial dos receptores serotoninérgicos e antagonismo glutamatérgico, tendo propriedades calmantes e sedativas (GUADAGNA S, et al., 2020). Seu uso vem sendo considerado alternativa e/ou adjuvante à fármacos para tratamento de desordens do sono, tendo como grande vantagem os mínimos efeitos colaterais comparado a outras classes com igual objetivo (PALMIERI G, et al., 2017).

\section{OBJETIVO}

Revisar a literatura científica em busca de unir informações acerca do que se têm de mais recente sobre o uso da valeriana como alternativa na abordagem terapêutica de distúrbios do sono.

\section{MÉTODO}

Revisão integrativa sobre o fitoterápico Valeriana no manejo de distúrbios do sono. Plataformas utilizadas: BVS e Pubmed. Pesquisa por "(Valeriana officinalis) AND (Sleep)": 339 artigos encontrados. Inclusão: artigos publicados nos últimos 5 anos que abordam uso da Valeriana nos distúrbios do sono. Critérios de exclusão: artigos que não tratam de estudos em humanos. Número final de artigos excluindo-se os repetidos: 16.

\section{REVISÃO BIBLIOGRÁFICA}

Os efeitos da Valeriana no sono medidos por avaliações objetivas foram pouco significativos e por avaliações subjetivas apresentaram resultados positivos e negativos (GUADAGNA S, et al., 2020). A Valeriana apresenta grande segurança, com raros e insignificantes efeitos adversos (GUADAGNA S, et al., 2020). Alguns estudos sobre o uso da Valeriana com populações específicas como mulheres pós-menopausa e pacientes com síndrome das pernas inquietas apresentaram resultados significativos em alguns critérios objetivos e subjetivos, entretanto as amostras foram pequenas (100 e 37 indivíduos respectivamente) (BEGA D e MALKANI R, 2016 e KHADIVZADEH T, et al., 2018). Estudos apontam ainda que a associação com outros medicamentos pode garantir melhorias além do controle do sono como ansiedade (na associação com eschscholtzia), irritabilidade, dificuldade de concentração e intensidade da fadiga (na associação com Hop e com jujube) (ABDELLAH SA, et al., 2019; PALMIERI G, et al., 2017). 


\section{CONSIDERAÇÕES FINAIS}

A Valeriana possui achados positivos sozinha ou associada a outros fitoterápicos, embora seja menos eficaz que os benzodiazepínicos no tratamento de distúrbios do sono. Outrossim, não está associada a efeitos adversos significativos. Por fim, diante de resultados pouco esclarecedores, para compreender melhor a Valeriana, necessita-se de estudos padronizados mais longos e em grupos amostrais mais heterogêneos.

\section{REFERÊNCIAS}

1. ABDELLAH SA et al. A combination of Eschscholtzia californica Cham. and Valeriana officinalis L. extracts for adjustment insomnia: A prospective observational study. J Tradit Complement Med, 2019; 10(2): 116-123.

2. BEGA D, MALKANI R. Alternative treatment of restless legs syndrome: an overview of the evidence for mind-body interventions, lifestyle interventions, and neutraceuticals. Sleep Med, 2016; 17(1): 99-105.

3. GUADAGNA S, et al. Plant Extracts for Sleep Disturbances: A Systematic Review. Evid Based Complement Alternat Med, 2020; 2020(1): 1-9.

4. KHADIVZADEH T, et al. A Systematic Review and Meta-analysis on the Effect of Herbal Medicine to Manage Sleep Dysfunction in Peri- and Postmenopause. J Menopausal Med, 2018; 4(2): 92-99.

5. PALMIERI G, et al. Evaluation of effectiveness and safety of a herbal compound in primary insomnia symptoms and sleep disturbances not related to medical or psychiatric causes. Nature and science of sleep, 2017; 9(1): 163.

6. SYS J, et al. Efficacy and safety of non-benzodiazepine and non-Z-drug hypnotic medication for insomnia in older people: a systematic literature review. European journal of clinical pharmacology, 2020; 76(3): 363-381. 
RESUMO SIMPLES: Relato de Experiência

Título: As tecnologias digitais como ferramenta de Educação em Saúde e divulgação das PICS: um relato de experiência

Autor/coautores: Ruthe Cecilia Lima da Silva, Laryssa Thaylle Santos da Silva, Ana Vitória Lima Ferreira, Amanda Leite Novaes, Ingrid Estefania Mancia de Gutiérrez

Instituição: Universidade Estadual de Feira de Santana (UEFS), Feira de Santana-Bahia.

Palavras-chave: Práticas Integrativas e Complementares, Pandemia, Atividade Extensionista

\section{INTRODUÇÃO}

As mídias digitais são veículos multiplicadores de informações (XAVIER F, et al., 2020), possibilitando uma nova perspectiva nos processos de ensino-aprendizagem (SCHILLINGER D, et al., 2020). Com distanciamento social, devido a pandemia por Covid-19, tornou-se fundamental a utilização de tecnologias para garantir a continuidade das intervenções de educação em saúde e divulgação das Práticas Integrativas e Complementares (PIC) pelo Programa de extensão Terapias não-Convencionais $(\mathrm{TnC})$ e você em uma Instituição de Ensino Superior da Bahia. As PICS foram implementadas através da Política Nacional de PIC em 2006 e hoje são 29 práticas inseridas no SUS, das quais algumas são ofertadas para a comunidade acadêmica assistida da Instituição (BRASIL, 2019).

\section{OBJETIVO}

Descrever a experiência de discentes, membros de um Programa de ensino, extensão e pesquisa em Práticas Integrativas e Complementares, com o uso das tecnologias digitais na disseminação de informações sobre as PICS no contexto de isolamento social.

\section{RELATO DE EXPERIÊNCIA}

Os cards ilustrativos, vídeos informativos e interativos sobre Plantas Medicinais, Fitoterapia, Dança Circular e Terapia Comunitária, assim como orientações quanto aos cuidados com Covid-19 foram elaborados utilizando os aplicativos Canva e Powtoon e divulgados nas redes sociais do programa (@tncevoce), da PROEX, Canal no Youtube e Facebook) e WhatsApp dos idosos cadastrados na Universidade Aberta à Terceira Idade.

Ainda foi possível organizar o I Simpósio Brasileiro on-line de PICS, com carga horária de 25 horas, realizado pela plataforma StreamYard com palestrantes especialistas em diversas práticas de diferentes estados e com transmissão ao vivo pelo canal do YouTube ( $\mathrm{TnC}$ e Você). O evento teve 21 palestrantes, 5.507 inscritos, 26.200 visualizações das 9 mesas temáticas durante transmissão ao vivo e mais 17.900 visualizações das mesas gravadas. Cada palestrante teve $1 \mathrm{~h}$ de fala e ainda 45 minutos reservados para que os mesmos respondessem as perguntas enviadas pelo público, o que favoreceu a interação. Apesar de online, o Simpósio também ofertou vivências das práticas de imposição de mãos, dança circular e bioenergética com o público.

\section{CONSIDERAÇÕES FINAIS}


A pandemia oportunizou um novo olhar sobre a extensão universitária. $O$ desenvolvimento de novas metodologias e didáticas demonstrou o poder de se reinventar e as diversas novas maneiras de se comunicar, transmitir conhecimento e se relacionar. É importante dar continuidade com manejo das tecnologias digitais a fim de globalizar informações sobre a temática para o maior número de pessoas, com alcance de informações seguras quanto às PICS.

\section{REFERÊNCIAS}

1. BRASIL. Ministério da Saúde. Práticas Integrativas e Complementares (PICS): quais são e para que servem. 2019. Disponível em: https://antigo.saude.gov.br/saude-de-a-z/praticas-integrativas-ecomplementares. Acessado em: 19 de outubro de 2020.

2. SCHILLINGER D, et al. From "Infodemics" to Health Promotion: A Novel Framework for the Role of Social Media in Public Health. American Journal of Public Health, 2020; 110(9): 1393-1396.

3. XAVIER F, et al. Análise de redes sociais como estratégia de apoio à vigilância em saúde durante a Covid19. Estudos Avançados, 2020; 34(99). 
RESUMO SIMPLES: Revisão Bibliográfica

Título: O uso clínico da apiterapia através das propriedades antibacterianas do mel

Autor/coautores: Rafael Cícero de Lima e Silva ${ }^{1}$; lasmine Andreza Basílio de Alves ${ }^{1}$; Terciana Marinho Maia Herculano Dias ${ }^{1}$; William Alves Bueno².

Instituição: Universidade Federal de Pernambuco (UFPE), Caruaru - Pernambuco'; Universidade Federal de São João del-Rei (UFSJ), Divinópolis-Minas Gerais².

Palavras-chave: Apiterapia; Antimicrobiano; Mel.

\section{INTRODUÇÃO}

A apiterapia é definida como o uso medicinal de produtos das abelhas, incluindo o mel (SENEL E e DEMIR E, 2018). O conhecimento dessa prática é histórico e na atualidade seu papel farmacológico e constituintes bioquímicos estão sendo investigados (NAYAKA NMDMW, et al., 2020). O mel é popularmente conhecido como um importante agente antimicrobiano. Esses poderes antibacterianos se devem à sua composição química, incluindo a presença de peróxido de hidrogênio, além de outros fatores não peróxidos. Destes, os compostos fenólicos, flavonoides e vários outros componentes fazem parte da atividade antibacteriana do mel (TUKSITHA L, et al., 2018).

\section{OBJETIVO}

Revisar a literatura científica na busca de estudos que abordam o uso da apiterapia através do mel e apontar propriedades antibacterianas por meio de seus parâmetros físico-químicos e possíveis usos clínicos em infecções por bactérias.

\section{MÉTODO}

Trata-se de uma revisão integrativa da literatura realizada nas bases de dados ScienceDirect e Pubmed. A busca utilizou os termos "APITHERAPY" e "ANTIBACTERIAL". Os critérios de inclusão da pesquisa foram: artigos em inglês e português, publicados entre 2016 e setembro de 2020 nas modalidades artigos originais ou revisão. Foram excluídos relatos de caso, artigos de opinião e artigos incompletos ou publicados fora do período delimitado pelos autores.

\section{REVISÃO BIBLIOGRÁFICA}

As diferenças na constituição química refletem na susceptibilidade bacteriana aos extratos de mel, indicando um efeito cepa-dependente. Para exercer a atividade antimicrobiana, os polifenóis presentes no mel alteram a permeabilidade das células microbianas, enquanto os flavonoides interrompem a função da membrana ou a síntese de DNA. Entretanto, correlações estatísticas negativas do conteúdo fenólico total e o conteúdo total de flavonoides das amostras sugerem que essas substâncias não são os únicos fatores que influenciam a bioatividade do mel, destacando assim o teor de peróxido de hidrogênio, a alta osmolalidade e a acidez também como os importantes agentes antibacterianos (NAYAKA NMDMW, et al., 2020). 
O uso do mel de origem indiana para tratar úlceras em pé diabético, por exemplo, demonstra eficácia contra bactérias como Pseudomonas aeruginosa, Staphylococcus aureus e Escherichia coli, além de auxiliar a cicatrização e efeito sinérgico com os antibióticos rifampicina e oxacilina (KATEEL $R$, et al., 2018).

\section{CONSIDERAÇÕES FINAIS}

Apesar da divergência nos parâmetros físico-químicos do mel, variando entre as espécies de abelha, todas apresentam algum grau de atividade contra microrganismos. Assim, somando essas vantagens à segurança da terapia, ao efeito sinérgico do mel com antibióticos e ao baixo custo, a prática deve ser estimulada.

\section{REFERÊNCIAS}

1. KATEEL R, et al. Antibacterial action of tropical honey on various bacteria obtained from diabetic foot ulcer. Complementary Therapies In Clinical Practice, 2018; 30: 29-32.

2. NAYAKA NMDMW, et al. Antioxidant and antibacterial activities of multiflora honey extracts from the Indonesian Apis cerana bee. Journal Of Taibah University Medical Sciences, 2020; 15(3): 211-217.

3. SENEL E, DEMIR E. Bibliometric analysis of apitherapy in complementary medicine literature between 1980 and 2016. Complementary Therapies in Clinical Practice, 2018; 31: 47-52.

4. TUKSITHA L, et al. Antioxidant and antibacterial capacity of stingless bee honey from Borneo (Sarawak). Journal Of Asia-Pacific Entomology, 2018; 21(2): 563-570. 
RESUMO SIMPLES: Relato de Experiência

Título: Relato de experiência da fundação de uma Liga Acadêmica de Medicina Integrativa em uma faculdade federal do Rio de Janeiro

Autor/coautores: Danielle de Oliveira Soeiro, Francisco José de Freitas

Instituição: Universidade Federal do Estado do Rio de Janeiro (UNIRIO), Rio de Janeiro-RJ

Financiamento: Inexistente

Palavras-chave: Liga Acadêmica, Desenvolvimento Discente, Medicina Integrativa

\section{INTRODUÇÃO}

O tema "Medicina Integrativa" é de crescente interesse na área da saúde. Cada vez mais, as pessoas que procuram e fornecem atendimento médico preferem métodos voltados ao cuidado integral, com estratégias menos agressivas e abordagem humanizada (BRASIL PNPIC, 2015). O currículo médico, no entanto, nem sempre é satisfatório na proposição desses temas, de modo que iniciativas estudantis, nomeadamente as ligas acadêmicas, tem especial relevância na comunicação entre sociedade e universidade (CAVALCANTE ASP, et al., 2018). Nesse contexto, estudantes do segundo período do curso de medicina tiveram a iniciativa de criar uma Liga Acadêmica de Medicina Integrativa em sua universidade.

\section{OBJETIVO}

Relatar a experiência dos discentes fundadores de uma Liga Acadêmica de Medicina Integrativa, em uma universidade federal do Rio de Janeiro, destacando suas motivações, desafios e percepções subjetivas do processo.

\section{RELATO DE EXPERIÊNCIA}

O currículo da universidade contém disciplinas obrigatórias chamadas "Práticas Integradoras", cujo objetivo é estabelecer maior diálogo entre as disciplinas do curso. A partir dessa proposta, desenvolveu-se a motivação para a criação da liga. Sabendo que a Medicina Integrativa é uma abordagem humana, centrada no relacionamento médico-paciente, baseada em evidências e que busca utilizar todas as alternativas terapêuticas possíveis e adequadas ao cuidado, percebeu-se que esse tema merecia maior destaque na universidade. Optou-se pela criação de uma liga acadêmica porque essa é uma ferramenta muito utilizada no país e destaca a autonomia estudantil, já que é orientada por docentes, mas gerida por discentes (SANTOS FF, et al., 2020). Na ocasião, a maior dificuldade foi o desenvolvimento de um estatuto que estabelecesse diretrizes claras, justas e sustentáveis, além de adequadas aos critérios estabelecidos pelo conselho regulamentador da universidade. Atualmente, 1 ano após a sua criação, já foram realizadas diversas atividades no âmbito do ensino, todas com excelente adesão da comunidade acadêmica, além de projetos iniciados pelas diretorias de pesquisa e extensão, e dobrou a quantidade de ligantes.

\section{CONSIDERAÇÕES FINAIS}


Até o momento, as atividades da liga - palestras, seminários, workshops, rodas de conversa, jornadas acadêmicas - propiciaram conexões dos ligantes com profissionais altamente qualificados e com estudantes de outros períodos, inclusive de universidades diferentes. A maior dificuldade dos ligantes encontra-se na gestão do tempo dedicado à liga, para que não prejudique a dedicação às demais atividades curriculares ou o tempo necessário de lazer, autocuidado e descanso.

\section{REFERÊNCIAS}

1. BRASIL. Política Nacional de Práticas Integrativas e Complementares. 2015. Disponível em: http://bvsms.saude.gov.br/bvs/publicacoes/politica_nacional_praticas_integrativas_complementares_2e d.pd. Acessado em: 10 de outubro de 2020.

2. CAVALCANTE ASP, et al. As Ligas Acadêmicas na Área da Saúde: Lacunas do Conhecimento na Produção Científica Brasileira. Revista Brasileira de Educação Médica, 2018; 42(1): 197-204.

3. SANTOS FF, et al. Desempenhos na Área de Competência Educação em Saúde: Autoavaliação de Estudantes de Medicina. Revista Brasileira de Educação Médica, 2020; 44(3): 0085. 
RESUMO SIMPLES: Revisão Bibliográfica

Título: Medicina Tradicional Chinesa e sua relação com o tratamento de COVID-19: revisão integrativa

Autores/Coautores: Dalva Mendes de Queiroz Carneiro Leão, lasmine Andreza Basilio dos Santos Alves.

Instituição: Universidade Federal de Pernambuco (UFPE), Caruaru-PE

Palavras-Chave: Medicina Tradicional Chinesa; Coronavirus; COVID-19.

\section{INTRODUÇÃO}

A COVID-19 é uma doença causada pelo SARS-CoV-2, vírus do gênero Betacoronavirus com RNA de fita simples. Um surto dessa doença começou na China onde o protocolo de tratamento enfatiza a combinação de Medicina Tradicional Chinesa (MTC) com terapia convencional. A MTC combina filosofia e controle de doenças antigas e tratamentos com eficácia comprovada para diferentes patologias. O conceito geral e os métodos de tratamento são baseados na diferenciação da síndrome, que é a característica mais significativa e essencial (HUANG F, et al., 2020; HUANG YF, et al., 2020).

\section{OBJETIVO}

Revisar a literatura científica na busca de estudos que abordam o manejo e o tratamento de pacientes diagnosticados com COVID-19 através da Medicina Tradicional Chinesa e que demonstrem a eficácia ou não dessa terapia.

\section{MÉTODO}

Trata-se de revisão integrativa da literatura realizada nas bases de dados ScienceDirect e Pubmed. A busca utilizou os termos "traditional chinese medicine" AND "SARS". Os critérios de inclusão da pesquisa: artigos em inglês e português, publicados entre janeiro e setembro de 2020 nas modalidades artigos originais ou de revisão. Foram excluídos relatos de caso, artigos de opinião e artigos incompletos ou publicados fora do período delimitado pelos autores.

\section{REVISÃO BIBLIOGRÁFICA}

Na China, os Medicamentos Chineses (MCs), fitoterápicos fundamentados na MTC, são estratégia para a prevenção e tratamento de COVID-19 em diferentes estágios (HUANG F, et al., 2020).

Dentre os MCs mais usados para a COVID-19 no país, diferenciados em decocções, cápsulas ou injeções de ervas determinadas, tiveram ênfase especial pelo China State Drug Administration a cápsula de Lianhua Qingwen e os grânulos de Huashi Baidu pelo notável alívio sintomático além da diminuição do tempo de reabilitação e da taxa de transferência de casos leves para graves (HUANG YF, et al., 2020; WANG WY, et al., 2020).

Os compostos ativos são direcionados a alvos virais ou do hospedeiro, dessa forma os MCs podem tratar COVID-19 ao direcionar a ligação a proteínas Spike, ACE2, 3CLpro, PLpro e RdRp por docking molecular, com foco em seis compostos: quercetina, andrographolide, ácido glicirrízico, baicalina, álcool de patchouli e luteolina (HUANG F, et al., 2020). 


\section{CONSIDERAÇÕES FINAIS}

O uso de fitoterápicos chineses em grupos de alto risco constitui forma alternativa de tratar COVID-19 e se mostra importante no tratamento complementar. Essa prática tem grande potencial pois acumulou experiências de anos no tratamento de doenças pandêmicas. Estudos rigorosos são necessários para confirmar o potencial efeito da MTC no tratamento do COVID-19.

\section{REFERÊNCIAS}

1. GUO, YR et al. The origin, transmission and clinical therapies on coronavirus disease 2019 (COVID-19) outbreak-an update on the status. Military Medical Research; 2020 7(1): 1-10.

2. REN, J et al. Traditional Chinese medicine for COVID-19 treatment. Pharmacological research, 2020; 155: e104743.

3. XU, J, ZHANG, Y. Traditional Chinese medicine treatment of COVID-19. Complementary Therapies in Clinical Practice, 2020; 39: e101165.

4. YANG, $Y$ et al. Traditional Chinese medicine in the treatment of patients infected with 2019-new coronavirus (SARS-CoV-2): a review and perspective. International journal of biological sciences, 2020; 16 (10): e1708. 
RESUMO SIMPLES: Relato de Experiência

Título: Relato de experiência da publicação de infográficos sobre o uso de plantas medicinais com potencial de uso no tratamento complementar do diabetes

Autor/coautores: Daniela Blank Barz, Daniel Costa Schwanck, Tássia Racki Vasconcelos, Teila Ceolin

Instituição: Faculdade de Enfermagem, Universidade Federal de Pelotas (UFPel), Pelotas - Rio Grande do Sul.

Financiamento: Pró-Reitoria de Extensão e Cultura (PREC), UFPel, com uma bolsa de extensão.

Palavras-chave: Plantas Medicinais, Diabetes Mellitus, Terapias Complementares.

\section{INTRODUÇÃO}

Os recursos terapêuticos que podem ser utilizados para o tratamento do diabetes mellitus (DM) incluem desde o tratamento farmacológico, mudanças no estilo de vida, ao uso de Práticas Integrativas e Complementares (PICs) (BRASIL, 2019). As PICs auxiliam no cuidado à saúde, entre elas estão as plantas medicinais. Dessa forma, o Projeto de Extensão Práticas Integrativas e Complementares na Rede de Atenção em Saúde (PE-PIC-RAS), Faculdade de Enfermagem, com atuação desde 2017, utilizou da Tecnologia da Informação para disseminar conhecimento sobre plantas medicinais com potencial hipoglicêmico, visto que as atividades de extensão presenciais não são viáveis devido ao distanciamento social imposto pela COVID19 (OLIVEIRA FLB e ALMEIDA JÚNIOR JJ, 2015).

\section{OBJETIVO}

Relatar a experiência dos integrantes do PE-PIC-RAS na elaboração e publicação de infográficos sobre plantas medicinais com potencial hipoglicêmico nas redes sociais, Instagram e Facebook, a fim de difundir o conhecimento à população durante a pandemia.

\section{RELATO DE EXPERIÊNCIA}

$\mathrm{Na}$ ação desenvolvida pelos integrantes do PE-PIC-RAS foi realizada uma revisão narrativa da literatura intitulada "Plantas medicinais com potencial para o tratamento complementar da diabetes". Após, foram selecionadas informações sobre quatro plantas medicinais: melão-de-são-caetano (Momordica charantia L.), pata-de-vaca (Bauhinia forficata Link), abacate (Persea americana Mill.) e couve (Brassica oleracea L.). Nessa viu-se que essas plantas possuem potencial hipoglicêmico, possibilitando serem utilizadas no tratamento complementar do diabetes mellitus (ASSIS JP, et al., 2015; LÓPEZ RES e SANTOS BC, 2015; NJATENG GSS, et al., 2018; ZANZINI AP, et al., 2020). Depois da pesquisa, deu-se a elaboração de infográficos editados no programa Canva e divulgados nas redes sociais do PE-PIC-RAS, Instagram e Facebook, com objetivo de levar conhecimento às pessoas através das mídias sociais.

A publicação ocorreu dia 28 de setembro de 2020 e até 6 de outubro obteve-se um resultado equivalente a 61 curtidas, 10 compartilhamentos e 294 pessoas alcançadas no Instagram. Já no Facebook, totalizou-se 47 curtidas, 98 compartilhamentos, 5 comentários, 957 visualizações e 16.954 pessoas alcançadas. Assim, foi possível observar que no Facebook o alcance foi expressivo, comparado ao Instagram. 


\section{CONSIDERAÇÕES FINAIS}

A ação desenvolvida possibilitou ampliar o conhecimento dos extensionistas sobre as plantas medicinais com potencial para o tratamento complementar da diabetes, bem como, divulgar essas informações por meio das redes sociais do PE-PIC-RAS para que a população tivesse acesso aos conteúdos, mesmo durante a pandemia. Desta forma, os objetivos do presente estudo foram alcançados.

\section{REFERÊNCIAS}

1. ASSIS JP, et al. Avaliação biométrica de caracteres do melão de São Caetano (Momordica charantia L). Revista Brasileira de Plantas Medicinais, 2015; 17(4): 505-514.

2. BRASIL. Diretrizes da Sociedade Brasileira de Diabetes 2019-2020. 2019 Disponível em: https://www.diabetes.org.br/profissionais/images/DIRETRIZES-COMPLETA-2019-2020.pdf Acessado em: 29 de agosto de 2020.

3. LÓPEZ R, SANTOS BC. Bauhinia forficata Link (Fabaceae). Revista Fitos, 2015; 9(3): 161-252.

4. NJATENG GSS, et al. Antidiabetic potential of methanol extracts from leaves of Piper umbellatum L. and Persea americana Mill. Asian Pacific Journal of Tropical Biomedicine, 2018; 8(3): 160-165.

5. OLIVEIRA FLB, ALMEIDA JJ. Extensão universitária: contribuições na formação de discentes de Enfermagem. Revista Brasileira de Pesquisa em Saúde, 2015; 17(1): 19-24.

6. ZANZINI AP, et al. Compostos bioativos presentes em couve-manteiga (Brassica oleracea L.) em três estádios de desenvolvimento e comparação das suas capacidades antioxidantes. Research, Society And Development, 2020; 9(7): e391974242. 
RESUMO SIMPLES: Relato de Experiência

Título: Formação e Capacitação em Reiki: Um relato de experiência de estudantes membros de uma Liga Acadêmica de Práticas Integrativas e Complementares

Autor/coautores: Bruno Souza de Lima ${ }^{1}$, Carolina Mendes Barbieri ${ }^{1}$, Júlia Corrêa e Ferreira ${ }^{1}$, William Alves Bueno' 1

Instituição: Universidade Federal de São João del-Rei (UFSJ), Divinópolis-Minas Gerais

Palavras-chave: Formação em Reiki, Práticas Integrativas, Liga Acadêmica

\section{INTRODUÇÃO}

A terapia Reiki é uma prática baseada na imposição das mãos para canalização da energia vital, visando o bem-estar físico e mental (BRASIL, 2020). Nos últimos anos, observou-se o crescimento de sua utilização em diferentes espaços de promoção da saúde, tais como hospitais e unidades básicas de saúde (SPEZZIA, S e SPEZZIA S, 2018). Além disso, o Reiki faz parte da Política Nacional de Práticas Integrativas e Complementares no SUS (BRASIL, 2017). Portanto, faz-se necessária maior gama de profissionais com formação nesta prática, na qual, para tornar-se um Terapeuta Reikiano, o profissional precisa passar pela capacitação com um mestre, cuja habilitação permite iniciar o interessado na terapia Reiki.

\section{OBJETIVO}

Relatar a experiência da organização de cursos de certificação em terapia Reiki realizados por uma Liga Acadêmica de Práticas Integrativas e Complementares (LAPIC) de uma universidade pública mineira no ano de 2019.

\section{RELATO DE EXPERIÊNCIA}

Durante um final de semana de setembro e dois dias letivos de dezembro de 2019, a LAPIC realizou três edições do curso de capacitação em terapia Reiki, em parceria com um mestre reikiano habilitado. Os inscritos foram iniciados em Reiki tradicional Usui/tibetano no nível 1 "O Despertar Shoden", o qual habilita a praticar a terapia natural Reiki. Além da iniciação, nos cursos foram realizadas trocas de níveis para participantes previamente iniciados. Ocorreram as trocas para os níveis 2 "Okuden a Transformação" com habilitação em envio de Reiki a distância; 3a "Mestre Interior Shinpiden" com habilitação para envio de Reiki para multidões e manuseio de todas as técnicas referentes a esse nível; e 3b "Mestre Curador Gokukaiden" com habilitação para iniciar outras pessoas no Reiki método Usui. Os cursos foram organizados pelos estudantes da universidade, membros da LAPIC, e recebeu inscritos de diferentes municípios da região. A instituição de ensino abriu as portas do seu campus para a entrada dessa prática integrativa no município, resultando na formação de 139 reikianos, entre novos terapeutas e trocas de níveis.

\section{CONSIDERAÇÕES FINAIS}

O Reiki é uma prática integrativa e complementar em saúde de baixo custo e boa aceitação pela não utilização de metodologia invasiva e medicamentosa. Ações realizadas na formação de novos terapeutas reikianos são importantes por possibilitar uma maior gama de profissionais para atuarem nas diferentes 
instâncias da saúde. Nesse sentido, os cursos promovidos pela LAPIC contribuíram com a disseminação da terapia Reiki no município e região da universidade.

\section{REFERÊNCIAS}

1. BRASIL. Portaria $\quad \mathrm{n}^{\circ}$ 2017. Disponível em: https://bvsms.saude.gov.br/bvs/saudelegis/gm/2017/prt0849_28_03_2017.html acessado em: 11 de outubro de 2020.

2. BRASIL. Práticas Integrativas. Secretaria de Atenção Primária à Saúde. Disponível em: https://aps.saude.gov.br/ape/pics/praticasintegrativas. Acessado em: 11 de outubro de 2020.

3. SPEZZIA S, SPEZZIA S. O uso do Reiki na assistência à saúde e no Sistema Único de Saúde. R. Saúde Públ. 2018; 1(1): 108-115. 
RESUMO SIMPLES: Relato de Experiência

Título: Experiência acadêmica da aplicação da Prática Integrativa Reiki através de um projeto de extensão

Autor/coautores: Larissa de Freitas Vilela', Bruna Moreira da Silva', Marcela Regina Azevedo de Castro Oliveira ${ }^{1}$, Moisés Fiúsa Menezes ${ }^{1}$, William Alves Bueno¹.

Instituição: Universidade Federal de São João del-Rei (UFSJ), Divinópolis-Minas Gerais .

Palavras-chave: Reiki; Projeto de extensão; Práticas Integrativas e Complementares.

\section{INTRODUÇÃO}

Com o interesse de maior conhecimento sobre as Práticas Integrativas e Complementares em Saúde (PICS), estudantes de uma universidade pública mineira fundaram uma Liga Acadêmica de Práticas Integrativas e Complementares (LAPIC). As atividades da liga visam três áreas: Extensão, Ensino e Pesquisa. A terapia de Reiki é uma prática complementar, que envolve a imposição das mãos para trocas de energias (BARBOSA GP, et al., 2016). Que assegura qualidade, segurança e eficácia (SPEZZIA S e SPEZZIA S, 2018). Através da área de Extensão da LAPIC foram inseridos o Reiki presencial e a distância, realizados por terapeutas docente e estudantes reikianos integrando bem-estar para a comunidade (SOUZA IN, et al., 2020).

\section{OBJETIVO}

Apresentar o funcionamento de um projeto de extensão de Reiki realizado com estudantes do ambiente acadêmico, organizado por alunos e docentes dos cursos de saúde de uma universidade pública mineira.

\section{RELATO DE EXPERIÊNCIA}

O projeto de extensão de Reiki, aprovado pela Pró-reitora de extensão da universidade em 2017, tem como propósito a melhoria da saúde da população. A divulgação da Terapia Reiki consta como um dos objetivos do projeto, estimulando a curiosidade de pessoas, e trabalhando no reconhecimento desta prática na comunidade. Isso faz com que surja mais Terapeutas Reiki, que também é objetivo do projeto, que oferece curso de capacitação para novos Terapeutas. Em parceria junto com a Assistência Estudantil da universidade, alunos que são encaminhados para atendimento da Assistência, recebem um convite para participar de sessões de Reiki presencial, para um tratamento ainda mais eficiente.

As comunidades intra e extra acadêmicas podem ter acesso ao Reiki na modalidade a distância, com a possibilidade de escrever e enviar para a liga um relato de experiência para expor os efeitos desta terapia. Diante dos vários relatos recebidos, foi identificado que o Reiki auxiliou na rotina de todos, foi eficaz complementando tratamentos e beneficiou os alunos que compartilharam redução de sintomas de ansiedade e outras doenças.

\section{CONSIDERAÇÕES FINAIS}

As PICS são cada vez mais utilizadas no campo da saúde. Por isso, a satisfação de exercer projetos na área é imensa. Com as experiências relatadas através do Reiki, percebemos que o projeto está agregando conhecimento e experiência na vida de estudantes e comunidade, contribuindo positivamente para a formação 
de futuros profissionais. Portanto, nota-se a importância em investimentos em pesquisas e atendimentos da prática, para ampliar esta terapia.

\section{REFERÊNCIAS}

1. SPEZZIA S, SPEZZIA S. O uso do Reiki na assistência à saúde e no Sistema Único de Saúde. Revista Saúde, 2018. 1(1): 108-115.

2. BARBOSA GP, et al. Reiki como prática integrativa e complementar: uma revisão integrativa. Revista Eletrônica Acervo Saúde, 2016; 8(3), 893-897.

3. SOUZA IN, et al. Produção científica acerca da Política Nacional de Práticas Integrativas e Complementares. Revista Eletrônica Acervo Saúde, 2020; 12(10) e4386. 
RESUMO SIMPLES: Relato de Experiência

Título: Uso da Erythrina mulungu como terapia complementar para ansiedade sequente da pandemia de COVID19 na zona rural do Agreste Pernambucano

Autor/coautores: Mylena Félix dos Santos; Myllena Cabral Marinho Pereira.

Instituição: Universidade de Pernambuco (UPE), Caruaru - Pernambuco.

Palavras-chave: Erythrina Mulungu, Ansiedade, Terapia Complementar.

\section{INTRODUÇÃO}

A pandemia de COVID19 trouxe várias mudanças no modo de viver, tendo como consequência o aumento de impactos psicológicos, como ansiedade, ao lidar com um ócio que a população não estava habituada (FARO A, et al., 2020). Sendo assim, a Erythrina mulungu tem sido utilizada como terapia complementar para a ansiedade, devido a suas propriedades terapêuticas ansiolíticas no sistema nervoso central tendo um efeito semelhante aos benzodiazepínicos. A casca é a principal parte utilizada para o preparo de chá, podendo ser encontrada na sua forma natural ou em pó. Dentre outros preparos encontramos o extrato, a tintura e diversas formulações de fitoterápicos (PALUMBO CFG, et al., 2016; BRASIL, 2015).

\section{OBJETIVO}

Relatar a experiência do uso da Erythrina mulungu como terapia complementar para ansiedade decorrente das mudanças do viver trazidos com a pandemia de COVID19 em uma população rural do Agreste Pernambucano.

\section{RELATO DE EXPERIÊNCIA}

Em meio à pandemia de COVID19, várias pessoas passaram pelo atendimento nutricional individual e compartilhado de um Núcleo Ampliado de Saúde da Família. Algumas destas relataram desenvolver ou agravar a ansiedade durante a pandemia devido ao medo e tédio. Estudos indicam que a pandemia os transtornos mentais como ansiedade e depressão podem ser desencadeados pelo isolamento e quarentena (LIMA CKT, et al., 2020; PANCANI L, et al., 2020). Todas as pessoas atendidas também relataram ocupar a ociosidade com a alimentação excessiva e/ou uso de bebidas alcoólicas, ocasionando em ganho de peso considerável e desenvolvimento de distúrbios metabólicos.

Os usuários receberam orientações nutricionais com ênfase no autocuidado alimentar, foi incentivada a prática de atividade física, e em alguns casos houve acompanhamento psicológico. Foi feito o estímulo do uso do chá da casca da Erythrina mulungu como terapia complementar, visto que é uma planta comum nos territórios e comumente utilizada e indicada pelos moradores mais antigos. Todas as pessoas relataram melhora do sono e de episódios ansiosos após o uso do chá associado a outros cuidados em saúde.

\section{CONSIDERAÇÕES FINAIS}

Os usuários responderam bem aos cuidados em saúde compartilhados com a equipe, e a experiência tem motivado tanto os profissionais como os pacientes a continuarem utilizando outras Práticas Integrativas e Complementares em Saúde no cuidado ofertado. Além disso, o uso da Erythrina mulungu dá voz aos saberes 
populares dos territórios rurais, reconhecendo e valorizando a importância das plantas medicinais nas práticas de cuidado.

\section{REFERÊNCIAS}

1. BRASIL. Monografia Da Espécie Erythrina Mulungu (Mulungu). Ministério da Saúde. 2015. Disponível em: https://portalarquivos2.saude.gov.br/images/pdf/2017/setembro/11/Monografia-Erythrina.pdf. Acessado em: 15 de outubro de 2020.

2. FARO A, et al. COVID-19 e saúde mental: a emergência do cuidado. Revista Estudos de Psicologia, 2020; 37: e200074.

3. LIMA CKT, et al. The emotional impact of coronavirus 2019-Ncov (new Coronavirus Disease). Psychiatry Research, 2020; 287: e112915.

4. PALUMBO CFG, et al. Erythrina mulungu Mart. ex Benth e Erythrina velutina Willd. - Aspectos farmacológicos e perspectiva antroposófica de plantas brasileiras. Arte Médica Ampliada, 2016; 36(4): 152-161.

5. PANCANI L, et al. Forced social isolation and mental health: a study on 1006 Italians under COVID-19 quarantine. PsyArXiv Preprints, 2020; 1: 1-22. 
RESUMO SIMPLES: Revisão Bibliográfica

Título: Benefícios da aromaterapia com óleo de lavanda na redução da ansiedade

Autor/coautores: Carmem Isaura Salles do Nascimento; Alícia Calinne Melo Santos; Ana Caroline Gusmão de Matos; Nathalia Costa Macedo Noronha; Luana Godinho Maynard.

Instituição: Universidade Tiradentes (UNIT), Aracaju-Sergipe.

Palavras-chave: Aromaterapia; Benefícios; Lavanda.

\section{INTRODUÇÃO}

A aromaterapia consiste em um recurso terapêutico amplamente utilizado na atualidade e tem como definição ser a arte e a ciência que visa a saúde e o bem estar do corpo, da mente e das emoções. Em diversas áreas da saúde e setores a aromaterapia vem sendo utilizada com o intuito, por exemplo, de reduzir a ansiedade, estresse e melhorar o sono (DOMINGOS TS e BRAGA EM, 2015). Os óleos essenciais (OE) de diversas plantas são extraídos e a partir de seu aroma natural busca-se a melhora dos sintomas listados (MONTIBELER J, et al., 2018).

\section{OBJETIVO}

Realizar uma revisão sistemática da literatura científica existente sobre os benefícios do uso da aromaterapia no tratamento da ansiedade que repercute na qualidade de vida dos indivíduos, principalmente a respeito do óleo de lavanda.

\section{MÉTODO}

Foram selecionados para essa revisão sistemática o tema; descritores: aromaterapia, lavanda; as bases de dados de pesquisa PubMed e Scielo e periódicos. A busca aconteceu em outubro de 2020, sendo encontrados 25 artigos científicos, dos quais 3 foram incluídos. Critérios de inclusão: idioma (Português ou Inglês); recorte temporal (2015 até 2020); textos na íntegra. Critérios de exclusão: não abordar a aromaterapia; não ter relação com a temática proposta.

\section{REVISÃO BIBLIOGRÁFICA}

A aromaterapia é aplicada com o uso dos OE via dérmica ou inalatória. Segundo estudos, a maior eficácia dos efeitos benéficos ocorre por inalação do OE. Suas substâncias atuam no sistema nervoso simpático e no parassimpático, o que resulta em redução da ansiedade, estresse, pressão arterial, confere maior qualidade ao sono e melhora a insônia (VILELA VC, et al., 2017; MONTIBELER J, et al., 2018).

A redução da ansiedade e do estresse estão relacionados à essência da lavanda. Entre as substâncias componentes do óleo de lavanda estão o linalil e linalol, que se associam à proteção do sistema nervoso central (SNC), inibindo ações colinérgicas ao modificarem canais iônicos nas junções neuromusculares, além de interagirem com o GABA. Assim, a lavanda é benéfica e utilizada na enfermagem para redução do estresse, em pacientes psiquiátricos para reduzir ansiedade e melhorar distúrbios do sono (DOMINGOS TS e BRAGA EM, 2015). 


\section{CONSIDERAÇÕES FINAIS}

A partir do relato, conclui-se que a aromaterapia muito tem a contribuir com a saúde em geral dos indivíduos. Contudo, há poucos estudos publicados na literatura sobre seus benefícios e que a torne alvo de indicações como terapia alternativa em diversas áreas da saúde.

\section{REFERÊNCIAS}

1. DOMINGOS TS, BRAGA EM. Massage with aromatherapy: effectiveness on anxiety of users with personality disorders in psychiatric hospitalization. Rev. esc. enferm. USP, 2015; 49(3): 450-456.

2. MONTIBELER J, et al. Efetividade da massagem com aromaterapia no estresse da equipe de enfermagem do centro cirúrgico: estudo-piloto. Rev. esc. enferm. USP, 2018; 52, 03348.

3. VILELA VC, et al. What do Cochrane systematic reviews say about non-pharmacological interventions for treating cognitive decline and dementia? São Paulo Med. J, 2017; 135(3): 309-320. 
RESUMO SIMPLES: Revisão Bibliográfica

Título: A acupuntura como prática integrativa e complementar no tratamento de doença pulmonar obstrutiva crônica

Autor/coautores: Rafael Cícero de Lima e Silva ${ }^{1}$; Evellyn Beatriz Ferreira Gomes ${ }^{1}$; lasmine Andreza Basílio de Alves ${ }^{1}$; Samuel Nobre de Miranda'; William Alves Bueno².

Instituição: Universidade Federal de Pernambuco (UFPE), Caruaru - Pernambuco'; Universidade Federal de São João del-Rei (UFSJ), Divinópolis-Minas Gerais².

Palavras-chave: Acupuntura; DPOC; Doença Pulmonar Obstrutiva Crônica.

\section{INTRODUÇÃO}

A Doença Pulmonar Obstrutiva Crônica (DPOC) é um quadro de obstrução crônica e irreversível do fluxo de ar, caracterizado pela persistência de sintomas respiratórios e alteração de parâmetros respiratórios. Ademais, a DPOC possui grande relevância para a saúde pública, pois é responsável por uma alta taxa de morbimortalidade mundial. O manejo inclui uso de medicamentos e reabilitação pulmonar, entretanto alguns pacientes são refratários. Nesse contexto, o uso da acupuntura é amplamente relatado no alívio de sintomas de dispneia nas doenças respiratórias, especialmente em pacientes com DPOC devido à sua ampla indicação, poucos efeitos colaterais, segurança e economia (YU M, et al., 2019; XIAO X, et al., 2020).

\section{OBJETIVO}

Revisar a literatura científica na busca de estudos que abordam o uso da acupuntura como prática integrativa e complementar no tratamento de pacientes que possuem diagnóstico de doença pulmonar obstrutiva crônica.

\section{MÉTODO}

Revisão integrativa da literatura realizada nas bases de dados ScienceDirect e Pubmed. A busca utilizou os termos "Acupuncture" e "chronic obstructive pulmonary disease". Os critérios de inclusão da pesquisa foram: artigos em inglês e português, publicados entre 2016 e setembro de 2020 nas modalidades artigos originais ou revisão. Foram excluídos relatos de caso, artigos de opinião e artigos incompletos ou publicados fora do período delimitado pelos autores.

\section{REVISÃO BIBLIOGRÁFICA}

De acordo com as recomendações da Global Initiative for Chronic Obstructive Lung Disease (GOLD), os pacientes com DPOC classicamente recebem terapia medicamentosa aliada a exercícios e à fisioterapia respiratória. No entanto, uma parcela dos pacientes não apresenta resultados ao tratamento tradicional, mostrando-se refratários, além da possibilidade de apresentarem efeitos adversos. Nesse cenário, o uso da acupuntura como Prática Integrativa e Complementar (PIC) tem se mostrado seguro e promissor nos estudos. Embora o mecanismo de ação ainda não esteja claro, estudos clínicos apontam um efeito comparável ao tratamento medicamentoso em pacientes com DPOC moderada a grave. Os efeitos benéficos dessa PIC se traduzem na redução da inflamação imunomediada da DPOC, melhora da função pulmonar, além da redução 
de quadros sintomáticos de falta de ar, necessitando de uma menor quantidade de oxigênio e ventilação (MAEKURA T, et al., 2019; XIAO X, et al., 2020).

\section{CONSIDERAÇÕES FINAIS}

A acupuntura é uma PIC segura, sendo potencializada pela associação com os métodos convencionais de tratamento e reabilitação respiratória. Ademais, mais estudos clínicos devem ser realizados no sentido de ampliar e estabelecer um melhor conhecimento dos benefícios e riscos do uso em pacientes com DPOC.

\section{REFERÊNCIAS}

1. MAEKURA T, et al. Clinical effects of acupuncture on the pathophysiological mechanism of chronic obstructive pulmonary disease during exercise. International Journal of Chronic Obstructive Pulmonary Disease, 2019; 14: 2787-2798.

2. XIAO X, et al. Acupuncture in the treatment of stable chronic obstructive pulmonary disease: A systematic review of randomised controlled trials. Journal of King Saud University - Science, 2020; 32: 3237-3248.

3. YU M, et al. Safety and efficacy of acupuncture for the treatment of chronic obstructive pulmonary disease: A systematic review protocol. Medicine (Baltimore), 2019; 98(37): e17112. 
RESUMO SIMPLES: Revisão Bibliográfica

Título: O Yoga como prática Integrativa e Complementar na recuperação de pacientes idosos acometidos pelo novo Coronavírus

Autor/coautores: Lucas Thadeu Silva de Ferreira Morais ${ }^{1}$ / Larissa de Freitas Vilela ${ }^{2}$, Maria Olívia de Araújo Pereira², Marcela Regina Azevedo de Castro Oliveira², William Alves Bueno².

Instituição: ${ }^{1}$ Faculdade Pitágoras, Divinópolis-Minas Gerais; ${ }^{2}$ Universidade Federal de São João del Rei (UFSJ), Divinópolis-Minas Gerais.

Palavras-chave: Yoga; Covid; PICS.

\section{INTRODUÇÃO}

O SARS-CoV-2, chamado de Novo Coronavírus foi inicialmente identificado em dezembro de 2019 levando a uma pandemia. Indivíduos idosos e com doenças concomitantes tem se mostrado mais suscetíveis ao desenvolvimento do quadro grave da doença, sendo assim considerados grupo de risco (PALMIERE L, et al., 2020.). O Yoga, Prática Integrativa e Complementar em Saúde (PICs) ofertada pelo SUS desde 2017, é capaz de ativar mecanismos curativos do próprio organismo de forma natural e a baixo custo, além de ser uma alternativa para pacientes idosos contaminados pelo SARS-CoV-2 que já fazem uso de diversas outras medicações (BUSHELL W, et al., 2020).

\section{OBJETIVO}

Revisar a literatura científica atual, de maneira qualitativa, para compreender a importância do Yoga como Prática Integrativa e Complementar (PICs) no tratamento e prevenção do Novo Coronavírus em pacientes idosos.

\section{MÉTODO}

Revisão integrativa de literatura com abordagem qualitativa. Utilizou bases eletrônicas: PubMED e BVS; com os descritores: Covid and Idosos, Covid and Yoga, Polifarmácia and idosos com revisão manual das referências dos trabalhos, e enfoque nos seguintes filtros: texto completo e gratuito, artigos dissertações, teses sem restrição para ano publicado ou idioma. Dentre as 7366 publicações encontradas sobre o tema, 30 foram objeto de avaliação e 13 seguiram para análise.

\section{REVISÃO BIBLIOGRÁFICA}

Os idosos são considerados a população mais suscetível a contrair o Novo Coronavírus por apresentarem mais comorbidades, muitas vezes demandando tratamentos com polifarmácia (uso concomitante de fármacos). A infecção pelo Novo Coronavírus associada a senilidade, contribui para o aumento dos processos inflamatórios do corpo, além de interferir negativamente no funcionamento do sistema imunológico natural do ser humano (MCQUEENIE R, et al., 2020).

O Yoga demonstra-se como uma efetiva ferramenta de auxílio no tratamento e controle de processos inflamatórios do corpo e é utilizado milenarmente como método de prevenção e controle da saúde através de técnicas e práticas descritas como Asanas (movimentos e posturas psicofísicas), Pranayamas (exercícios de controle do fluxo respiratório e energia corporal) e Meditação, que estimulam naturalmente as capacidades curativas do corpo humano (BUSHELL W, et al., 2020; TILLU G, et al., 2020; GOVINDARAJ R, et al., 2016). 


\section{CONSIDERAÇÕES FINAIS}

As técnicas de Yoga, têm se mostrado eficazes como tratamento complementar de pacientes idosos acometidos pelo Novo Coronavírus. Além de seu baixo custo, fácil acessibilidade e aplicabilidade, possui técnicas não invasivas e reduz a polifarmácia, que pode acarretar interações medicamentosas perigosas e fragilizar o corpo do paciente.

\section{REFERÊNCIAS}

1. PALMIERI L, et al. Clinical Characteristics of Hospitalized Individuals Dying With COVID-19 by Age Group in Italy. The Journals of Gerontology, 2020; 75(9):1796-1800.

2. BUSHELL W, et al. Meditation and Yoga Practices as Potential Adjunctive Treatment of SARS-CoV-2 Infection and COVID-19: A Brief Overview of Key Subjects. The Journal of Alternative and Complementary Medicine, 2020; 26(7): 547-556.

3. MCQUEENIE R, et al. Multimorbidity, polypharmacy, and COVID-19 infection within the UK Biobank cohort. Plos One, 2020; 15(8): 1-15.

4. TILLU G, et al. Public Health Approach of Ayurveda and Yoga for COVID-19 Prophylaxis. The Journal of Alternative and Complementary Medicine, 2020; 26(5): 360-364.

5. GOVINDARAJ R, et al.Yoga and physical exercise - a review and comparison. International review of psychiatry, 2016; 28(3): 242-253. 
RESUMO SIMPLES: Revisão Bibliográfica

Título: Importância da acupuntura no tratamento da COVID-19

Autor/coautores: Ana Caroline Gusmão de Matos/Alícia Calinne Melo Santos, Carmem Isaura Salles do Nascimento, Nathalia Costa Macedo Noronha, Luana Godinho Maynard.

Instituição: Univerdidade Tiradentes (Unit), Aracaju-Sergipe.

Palavras-chave: Acupuntura, COVID-19, Medicina Integrativa e Complementar.

\section{INTRODUÇÃO}

$\mathrm{Na}$ acupuntura, um componente da Medicina Tradicional Chinesa (MTC), quando uma agulha é inserida em um ponto específico, ocorre uma estimulação física traumática e, em seguida, a rede de regulação imunológica neuroendócrina é ativada (HUANG KY, et al., 2020). Por suas implicações benéficas, a acunputura tem sido proposta como prática complementar no tratamento da COVID-19 (CHEN Y, et al., 2020), doença infecciosa respiratória aguda ocasionada pelo vírus SARS-CoV-2 que cursa com uma vasta sintomatologia e cujo tratamento é ainda desconhecido (LIU WH, et al., 2020; WU L, et al., 2020).

\section{OBJETIVO}

Analisar a importância e a eficácia da acupuntura como tratamento integrativo e complementar na sintomatologia da COVID-19, em especial nas implicações respiratórias da patologia, já bem relatadas pela comunidade científica.

\section{MÉTODO}

Trata-se de uma revisão integrativa sobre o papel da acupuntura na terapêutica da COVID-19 realizada a partir da base de dados PubMed, utilizando os descritores "COVID-19" e "Acupuncture". Foram selecionados 6 dos 49 artigos encontrados. Os critérios de inclusão foram textos disponíveis na íntegra, publicado em 2020, em Português e Inglês. De exclusão, os que não abordaram nenhuma das técnicas de acupuntura (agulha, digitopressão, auricular, moxabustão).

\section{REVISÃO BIBLIOGRÁFICA}

A acupuntura ativa o sistema de defesa e reduz o tônus da musculatura lisa brônquica (WU L, et al., 2020), melhorando a dispneia. Ademais, ajuda no controle de ansiedade, náuseas, vômitos, insônia, leucopenia, dor e distensão abdominal (ZHANG B, et al., 2020; CHEN Y, et al., 2020). Diante disso, em países como a China, as diretrizes para COVID-19 associaram MTC e tratamentos convencionais (ZHANG B, et al., 2020).

Pontos de acupuntura podem suavizar o qi do fígado; fortalecer o baço; harmonizar o estômago; e controlar a pressão arterial ao inibir o sistema renina-angiotensina-aldosterona, regular a expressão da angiotensina, dilatar os vasos e reduzir a resistência periférica (HUANG KY, et al., 2020; LIU WH, et al., 2020). Também atua em mediadores febris centrais induzindo defervescência. Além disso, apresenta baixo risco de efeitos adversos, diferente das medicações empregadas no tratamento da COVID-19 como remdesivir, hidroxicloroquina e inibidores da via da interleucina-6 (IL-6), as quais podem ocasionar problemas cardíacos, hepáticos e renais (HUANG KY, et al., 2020). 


\section{CONSIDERAÇÕES FINAIS}

A combinação de acupuntura e tratamento convencional é pertinente na COVID-19. Esse regime combinado exibe efeito significativo sobre suas complicações hepáticas, renais, gastrointestinais, cardíacas e psíquicas. Sendo assim, essa terapia deve ser estimulada nos países em que o surto de COVID-19 persiste.

\section{REFERÊNCIAS}

1. CHEN Y, et al. Acupuncture for coronavirus disease 2019: A protocol for systematic review and meta analysis. Medicine, 2020; 99(40): e22231.

2. HUANG KY, et al. The efficacy of acupuncture for improving the side effects of COVID-19 western medicine treatments: A protocol for a systematic review and meta-analysis. Medicine, 2020; 99(28): e21185.

3. LIU WH, et al. Understanding of Guidance for acupuncture and moxibustion interventions on COVID-19 issued by China Association of Acupuncture-Moxibustion. World Journal of Acupuncture-Moxibustion, 2020; 30(1): 1-4.

4. WU L, et al. External treatment of traditional Chinese medicine for COVID-19: A protocol for systematic review and meta-analysis. Medicine, 2020; 99(39): e22316.

5. ZHANG B, et al. Acupuncture for breathlessness in COVID-19: a protocol for systematic review and metaanalysis. Medicine, 2020; 99(27): e20701. 
RESUMO SIMPLES: Revisão Bibliográfica

Título: A Terapia floral no controle do medo e ansiedade na Odontopediatria

Autores: Carla Cristina Nunes de Araujo1; Viviane Ferreira de Freitas Fraga²

Instituição: ${ }^{1}$ Universidade Federal de Sergipe; ${ }^{2}$ Universidade de Franca

Palavras-chave: Medo, Odontopediatria, Terapia floral.

\section{INTRODUÇÃO}

O tratamento odontológico, frequentemente, está relacionado a um quadro de ansiedade e apreensão infantil, decorrentes de situações reais ou imaginárias, como sensação inesperada de dor. (BATISTA TRM, et al., 2018). Dentre inúmeras técnicas comportamentais e medicamentosas para controle do medo odontológico infantil, observa-se aumento de indicações das práticas integrativas e complementares (PICs), dentre elas, a terapia floral, que visa o equilíbrio dos estados físico e emocional. (BAASTCHA B, et al., 2017). Essa é regulamentada pelo Conselho Federal de Odontologia (CFO), através da Resolução 82/2008, que trata dos requisitos para atuação do cirurgião-dentista.

\section{OBJETIVO}

Revisar a literatura científica sobre indicações terapêuticas das essências florais como método auxiliar no controle da redução do medo e ansiedade na abordagem odontológica em crianças, assim como sua posologia e interações.

\section{MÉTODO}

Revisão integrativa de literatura, de caráter descritivo, contemplou bases de dados eletrônicos - Cochrane Library, Scielo, Science Direct, Pubmed- entre maio e julho de 2020, utilizando-se descritores em português, inglês e espanhol: medo, Odontopediatria, terapia floral. Considerou-se, como critérios de inclusão, pesquisas publicadas a partir do ano de 2010, que abordaram floralterapia no controle da ansiedade e medo na Odontopediatria, excluídos estudos que não abordaram saúde bucal.

\section{REVISÃO BIBLIOGRÁFICA}

Na prática odontológica, a colaboração é essencial no atendimento e as PICs podem auxiliar no quadro de apreensão infantil, embora haja reduzido número de estudos que comprovem a sua efetividade, incluindo a Terapia floral (BAASTCHA B, et al., 2017).

Essa tem uso disseminado desde o século XX, a partir das pesquisas do médico inglês Edward Bach. Trata-se de terapia baseada nas propriedades curativas das plantas, por meio de uma solução hidroalcóolica administrada, geralmente, por via oral, tendo sua posologia fracionada, instituída dias antes do procedimento odontológico (SISTO M, et al. 2019). Sua ação visa estabelecer o equilíbrio psicofísico, sendo de baixo custo (FERNANDES NETO JA, et al., 2020).

Observou-se concordância na efetividade da floralterapia na redução do medo e ansiedade odontológica infantil, relacionando-a à indicação dos florais de Bach como Cherry Plum (Prunus cerasifera), Rock Rose 
(Helianthemum nummularium), Mimulus (Mimulus guttatus), Aspen (Populus tremula) e Rescue Remedy, sem relato de efeitos adversos (DIXIT e JASANI, 2020).

\section{CONSIDERAÇÕES FINAIS}

A Terapia Floral, aliada a restrição de efeitos adversos e baixo custo, apresenta inúmeras indicações terapêuticas na prática odontológica, especialmente na abordagem da ansiedade e medo infantil, ratificando a importância de incentivo a pesquisas científicas sobre seus benefícios na Odontopediatria.

\section{REFERÊNCIA}

1. BAATSCHA B, et al. Complementary and alternative therapies in dentistry and characteristics of dentists who recommend them. Complementary Therapies in Medicine, 2017; 35:64-69.

2. BATISTA TRM, et al. Medo e ansiedade no tratamento odontológico: um panorama atual sobre aversão na odontologia. SALUSVITA, Bauru, 2018: 37: 449-469.

3. CONSELHO FEDERAL DE ODONTOLOGIA. Resolução n. ${ }^{\circ} 87$, de 25 de setembro de 2008. Reconhece e regulamenta o uso pelo cirurgião-dentista de práticas integrativas e complementares à saúde bucal. Diário Oficial da União, Poder Executivo, Brasília, DF, 2008, Seção 1: 105- 7. Disponível em:www.crorn.org/noticias/ver/379. Acessado em 15 de junho de 2020.

4. DIXIT UB, JASANI RR. Comparison of the effectiveness of Bach flower therapy and music therapy on dental anxiety in pediatric patients: A randomized controlled study. J Indian Soc Pedod Prev Dent, 2020;38:71-78.

5. FERNANDES NETO JA, et al. Habilitação em terapia floral para cirurgiões-dentistas: uma análise por estados e regiões brasileiras. Archives of Health Investigation, 2019; 8: 576-579.

6. SISTO M, et al. Flores de Bach para el tratamiento de niños con gingivoestomatitis herpética aguda, MEDISAN, 2019; 23(5): 36-38. 
RESUMO SIMPLES: Estudo Original

Título: Terapias Complementares na promoção da saúde e apoio social no contexto universitário

Autor/coautores: Suellen Andrade Pereira; Vânia Regina Bressan; Adriana Teresa Silva Santos.

Instituição: Universidade Federal de Alfenas (UNIFAL-MG), Alfenas-Minas Gerais.

Palavras-chave: Terapias Complementares, Apoio Social, Promoção da Saúde.

\section{INTRODUÇÃO}

O ingresso no ensino superior implica em significativas mudanças na vida do estudante (SOUZA LK, et al., 2016). O suicídio, identificado como um problema de saúde pública prevalente entre estudantes universitários (SANTOS HGB, et al., 2017). Nesse sentido, demonstra-se uma população vulnerável. Dado esse contexto, surgiu programa de extensão em parceria com a Prefeitura Municipal a fim de atender a demanda dos estudantes de uma universidade pública e dentre as atividades, os Exercícios Orientais Terapêuticos (EOT). A EOT utiliza-se de técnicas como o do-in, o shiatsu, a yoga, a meditação e artes marciais (kung fu) orientadas pela Medicina Tradicional Chinesa (MTC).

\section{OBJETIVO}

Analisar as contribuições da prática Exercícios Orientais Terapêuticos para estudantes de uma Universidade Federal do Sul de Minas Gerais. Identificar como os participantes se sentem após a prática. Conhecer as características sociodemográficas dos estudantes participantes.

\section{MÉTODO}

Estudo qualitativo transversal (MINAYO MCS, 2017) com coleta de dados por grupo focal. A população corresponde a 25 participantes da EOT e a amostra final composta por 15 graduandos. Foram incluídos estudantes com idade maior ou igual a 18 anos e participantes por três meses ou mais da prática. A análise foi realizada por conteúdo temático. Aprovada pelo Comitê de Ética em Pesquisa (CEP) no 20397019.7.0000.5142.

\section{RESULTADOS}

O estudo demonstrou contribuições relacionadas a promoção da saúde com impacto no alívio do estresse e da ansiedade, na promoção do relaxamento, controle emocional, autoconhecimento e autonomia, bem como, em mudanças no estilo de vida dos participantes. Revelou-se através dos discursos ser uma prática integral ao contemplar aspectos físicos, emocionais e mentais e a importância na vida dos estudantes na manutenção da frequência na prática. Identificou-se ainda que a EOT impactou no apoio social através da ampliação da rede dos estudantes e da pertença ao grupo, junto a empatia e a visualização do professor como modelo de inspiração aos participantes.

\section{CONSIDERAÇÕES FINAIS}

Portanto, a prática da EOT ao valorizar e compreender os fundamentos cosmológicos orientais impactou de forma relevante na vida dos estudantes. Trata-se de um método inovador ao articular terapias 
complementares existentes numa prática única orientada pela integralidade e as necessidades ampliadas de saúde. Nesse sentido, constitui uma técnica que pode ser adotada por diversos grupos populacionais.

\section{REFERÊNCIAS}

1. MINAYO MCS. Amostragem e saturação em pesquisa qualitativa: consensos e controvérsias. Revista Pesquisa Qualitativa, 2017; 5(7): 1-12.

2. SANTOS HGB et al. Factors associated with suicidal ideation among university students. Revista LatinoAmericana de Enfermagem, 2017; 25: e2878.

3. SOUZA LK, et al. Adaptação à universidade em estudantes ingressantes na graduação em psicologia. Psicologia da Educação, 2016; 42: 35-48. 
RESUMO SIMPLES: Relato de Experiência

Título: Programa de Mindfulness durante Isolamento Social provocado pela pandemia do Sars-CoV-2: um relato de experiência

Autor/coautores: Rayanne Conceição dos Santos; Brunna Santos de Oliveira; Yanne Feitoza de Carvalho; Jefferson Ricardo Novaes de Souza; Murilo Marchioro.

Instituição: Universidade Federal de Sergipe (UFS), São Cristóvão- Sergipe

Palavras-chave: Meditação, Mindfulness, COVID-19.

\section{INTRODUÇÃO}

A pandemia do Sars-CoV-2 foi responsável por gerar perturbações psicológicas que dificultam seu enfrentamento (FARO A, et al., 2020). Com isso, a atenção plena ou mindfulness é um método de treinamento mental de meditação, praticado como estilo de vida, que exerce benefícios sobre a saúde, bem-estar e comportamento do indivíduo. Essa prática consiste na arte da observação e pode auxiliar na captação de padrões do pensamento do praticante (RAHAL GM, 2018). Desta forma, os programas de mindfulness favorecem a promoção da saúde, pois têm como princípios o desenvolvimento de autonomia e empoderamento das pessoas por meio do treinamento da atenção plena (DEMARZO MMP, 2015).

\section{OBJETIVO}

Apresentar um relato de experiência em um ciclo de aplicação da metodologia de Mindfulness no isolamento social, durante oito semanas, que é sugerido pelo livro "Atenção Plena: Mindfulness" de Mark Williams e Danny Penman.

\section{RELATO DE EXPERIÊNCIA}

A atividade surgiu mediante a nítida dificuldade de enfrentamento da pandemia do Sars-CoV-2, causador da COVID-19, em seu momento inicial. Teve a proposta de promover maior integração entre pessoas, através de um grupo de estudo sobre meditação Mindfulness, tendo como base de estudos o livro Atenção Plena.

Para que essa atividade fosse concretizada, a mesma foi dividida em: divulgação, execução e avaliação. A divulgação consistiu na informação e captação de interessados através do uso das redes sociais de uma liga acadêmica e preenchimento de formulário do Google Forms.

A sua execução compreendeu reuniões realizadas semanalmente, todos os Sábados às $17 \mathrm{~h}$. Cada semana era dedicada a discussão e repasse de atividades, que seriam realizadas ao longa da semana seguinte, seguindo a ordem dos capítulos do livro. Nesse momento também havia diálogos a respeito de como a meditação auxiliava no processo individual de enfrentamento às manifestações psicossomáticas, intensificadas devido à pandemia.

Na etapa de avaliação, foi realizada uma reunião extra, um mês após a finalização das 8 semanas estipuladas, para a avaliação do impacto da meditação. 


\section{CONSIDERAÇÕES FINAIS}

O programa de oito semanas de Mindfulness, introduziu o hábito de meditação no dia-a-dia dos participantes, sendo de grande importância para o enfrentamento de situações de estresse e ansiedade durante $o$ isolamento social. Além disso, o grupo tornou-se um espaço acolhedor para o compartilhamento de sentimentos, sensações e criação de relações afetivas, mesmo que de forma virtual.

\section{REFERÊNCIAS}

1. DEMARZO, MMP. Mindfulness e Promoção da Saúde. Revista Saúde na Comunidade, 2015; 2(3): e82.

2. FARO A, et al. COVID-19 e saúde mental: a emergência do cuidado. Estudos de Psicologia (Campinas), 2020; 37: e200074.

3. RAHAL, GM. Atenção plena no contexto escolar: benefícios e possibilidades de inserção. Revista Psicologia Escolar Educacional, 2018; 22(2): 347-358. 
RESUMO SIMPLES: Relato de Experiência

Título: As Práticas Integrativas e Complementares de Saúde (PICS) no alívio da dor crônica em pessoas com fibromialgia: um relato de experiência

Autor/coautores: Alana Gabriela Conceição Hora; Júlia Borges Giudice Monteiro; Rayanne Conceição dos Santos; Murilo Marchioro.

Instituição: Universidade Federal de Sergipe (UFS), São Cristóvão-Sergipe.

Palavras-chave: PICS; Fibromialgia; Fevereiro Roxo.

\section{INTRODUÇÃO}

A fibromialgia é uma síndrome caracterizada pela dor crônica difusa, etiopatogenia pouco esclarecida, associada à depressão, ansiedade, distúrbios de sono e humor (MELO G, et al., 2020). Apresenta sintomas prejudiciais à qualidade de vida, demandando tratamentos multidisciplinares (ARNOLD LM e CLAUW DJ, 2017).

As PICS corroboram significativamente no cuidado dos fibromiálgicos. Trabalhos demonstram contribuição dessas na qualidade do sono, alívio da dor e estresse psicossocial (ÇINAR HG e ALPAR ŞE, 2017; VAN GORDON W, et al., 2017; ARTIOLI DP, et al., 2019).

Assim, a Liga Acadêmica de PICS de uma universidade pública, participou da Campanha Fevereiro Roxo, a convite do programa de Enfermagem da mesma instituição de ensino (IES).

\section{OBJETIVO}

Relatar a experiência da participação de uma liga acadêmica de práticas integrativas e complementares em saúde em uma campanha para disseminação da importância e benefícios das PICS no tratamento continuado da fibromialgia.

\section{RELATO DE EXPERIÊNCIA}

O evento contou com três etapas: planejamento (seleção dos ligantes e práticas ofertadas); execução (realização das PICS no dia do evento e troca de saberes); e avaliação (reunião com os integrantes da ação para feedback).

No dia do evento, a Liga atuou em uma roda de conversa composta por pessoas diagnosticadas com a síndrome, uma doutoranda do grupo de pesquisa relacionado à temática e os integrantes do programa de Enfermagem da mesma IES. Durante a roda, houve a troca de experiências sobre como as pessoas lidam com a fibromialgia, o esclarecimento sobre essa síndrome, a importância da meditação e das demais PICS para o alívio das dores associadas. Posteriormente, a Liga realizou auriculoterapia, seguindo o protocolo para fibromialgia, e corredor de cuidados, sendo a aplicação do reiki no momento do corredor de cuidados (da prática). 
No decorrer da ação, os participantes relataram a importância da vivência, expressando gratidão pelo momento e pela troca de energias positivas. Após a ação, algumas pessoas com fibromialgia informaram que tiveram um sono restaurador, e ausência das dores no dia posterior.

\section{CONSIDERAÇÕES FINAIS}

Em suma, a participação da Liga na Campanha Mensal: fevereiro Roxo, teve um forte impacto na percepção dos ligantes, principalmente no que consiste a sensibilização, conhecimento e empatia relacionada à Fibromialgia, fatos que repercutem em ganhos pessoais e profissionais. Além disso, a ação cumpriu seus objetivos à medida que disseminou o conhecimento relativos às PICS e promoveu o autocuidado, através das três atividades abordadas.

\section{REFERÊNCIAS}

1. ARNOLD LM, CLAUW DJ. Challenges of implementing fibromyalgia treatment guidelines in current clinical practice. Postgraduate medicine, 2017; 129(7): 709-714.

2. ARTIOLI DP, et al. Auriculotherapy: neurophysiology, points to choose, indications and results on musculoskeletal pain conditions: a systematic review of reviews. Brazilian Journal of Pain, 2019; 2(4): 356361.

3. ÇINAR HG, ALPAR ŞE. Efficacy of Reiki Application in Fibromyalgia Patients. International Journal of Health Sciences \& Research, 2017; 7(10): 230-234.

4. MELO G, et al. Análise das comorbidades associadas à fibromialgia: uma revisão bibliométrica. Psic., Saúde \& Doenças, 2020; 21(2): 395-403.

5. VAN GORDON W, et al. Meditation awareness training for the treatment of fibromyalgia syndrome: A randomized controlled trial. British Journal of Health Psychology, 2017; 22(1): 186-206. 
RESUMO SIMPLES: Revisão Bibliográfica

Título: Acupuntura como recurso complementar no tratamento de feridas

Autor/coautores: Luan Mauricio de Lima; Simone Márcia Silva; Marcos Matheus Missias Silva; João Augusto da Silva; Gêssyca Adryene de Menezes Silva.

Instituição: Centro Universitário Tabosa de Almeida (ASCES-UNITA), Caruaru-Pernambuco

Palavras-chave: Acupuntura, Feridas, Lesão.

\section{INTRODUÇÃO}

A acupuntura vem crescendo com o passar do tempo, ganhando seu espaço e reconhecimento dentro das mais diversas áreas de saúde praticadas no ocidente. Ela se utiliza de várias técnicas e equipamentos que foram criados e/ou adaptados para atingir seu objetivo, seja ele prevenção ou tratamento de diversas doenças, disfunções e/ou lesões nos mais variados níveis psicossociais (TANO SS e SILVÉRIO-LOPES SM, 2013). Devido a sua popularidade a acupuntura passou a ser vista sob outras perspectivas e começou a ser aplicada concomitantemente com novos tratamentos assim como os clássicos (ORTUNHO VV, et al., 2015).

\section{OBJETIVO}

Revisar a literatura para evidenciar a técnica e conhecimentos da acupuntura chinesa para auxiliar no tratamento de feridas e lesões, independentemente de sua extensão, causa, profundidade e local acometido, seja em pessoas ou animais.

\section{MÉTODO}

Trata-se de uma revisão integrativa nas bases Scielo, Lilacs e BDNEF cruzando os descritores Acupuntura, Feridas, Lesão com o operador booleano AND. Foram encontrados 60 artigos utilizando os seguintes critérios de inclusão: artigos nos idiomas português, inglês e espanhol; publicações de 2015 a 2020. Foram excluídos artigos sem adequação temática. Após a leitura dos títulos, resumos e artigos na íntegra foram selecionados 2 artigos para compor essa revisão.

\section{REVISÃO BIBLIOGRÁFICA}

A acupuntura é uma técnica clássica do oriente que através de estímulos com pressão, massagem, mas principalmente agulhas e calor através da moxa faz a movimentação do Qi do indivíduo que a recebe com intuito de equilibrá-lo energeticamente, pois assim se chega ao estado de saúde desejável (GARCIA VC e PRADO CV, 2017). Através da técnica "cercar o dragão" ou "cerclagem do dragão" na qual o acupunturista insere um quantitativo $X$ de agulhas ao redor do local acometido por lesão ou ferida, sendo o número de agulhas dependente da extensão do tecido danificado, coloca-se as agulhas a alguns milímetros de distância da ferida e inclinadas para a mesma, podendo-se obter ótimos resultados na cicatrização de feridas e lesões no paciente, já que haverá uma maior movimentação e concentração de Qi para o local da aplicação, assim aumentando a regeneração tecidual (TANO SS e SILVÉRIO-LOPES SM, 2013).

\section{CONSIDERAÇÕES FINAIS}


Através dos textos lidos a técnica "cerclagem do dragão" pode ser utilizada de forma complementar no tratamento de feridas com bons resultados, uma vez que, com a utilização da técnica irá diminuir o tempo que o paciente precisa para favorecer a regeneração tecidual.

\section{REFERÊNCIAS}

1. GARCIA VC, PRADO CV. Use of moxibustion as an auxiliary treatment in wound healing of the snake Eunectes murinus (anaconda): case report. Arq. Bras. Med. Vet. Zootec., 2017; 69(6): 1560-1564.

2. ORTUNHO VV, et al. Associação do tratamento convencional de feridas com o uso da acupuntura em um Tucano- Toco. Relato de Caso. Revista Brasileira de Higiene e Sanidade Animal: RBHSA, 2015; 8(4): 110-119.

3. TANO SS, SILVÉRIO-LOPES SM. Eletroacupuntura e eletropuntura. Analgesia por Acupuntura, 2013; 22: 63-80. 
RESUMO SIMPLES: Relato de Experiência

Título: Impressões de discentes de medicina acerca da terapia comunitária integrativa como dispositivo para formação e prática médica ampliadas

Autor/coautores: Thanilly Silveira Macedo, Júlio Samuel Silva Souza, Daniel Bastos Alves Lima, Ângela Reis Teixeira, Patrícia Baier Krepsky.

Instituição:Universidade Federal da Bahia (UFBA). Vitória da Conquista-BA.

Palavras-chave: Educação Médica, Práticas Integrativas e Complementares, Terapia comunitária.

\section{INTRODUÇÃO}

Dada a complexidade humana o modelo biomédico, embora hegemônico, não atende completamente às demandas populacionais, que buscam progressivamente por outras modalidades terapêuticas (CLIMACO LCC, et al., 2019). Nessa perspectiva, a inserção de práticas como a Terapia Comunitária Integrativa (TCI) na Política Nacional de Práticas Integrativas e Complementares (PNPIC) do Sistema Único de Saúde (SUS), através da Portaria 849/2017, visa promover saúde integral. Ademais, ressignifica os cuidados clínicos, possibilitando interação entre saberes científico e popular (NASCIMENTO MVN, 2017). Destarte, a incorporação de diferentes racionalidades médicas no SUS sinaliza necessidade de promover a formação de profissionais que atendam às novas demandas nos diferentes modelos de saúde (TEIXEIRA MZ, 2017).

\section{OBJETIVO}

Relatar a experiência vivenciada por discentes do curso de medicina sobre práticas Integrativas e Complementares, com enfoque na abordagem da terapia comunitária integrativa, correlacionando-a com a formação e prática médica ampliadas.

\section{RELATO DE EXPERIÊNCIA}

O contato com a TCl deu-se no componente "Práticas integrativas e complementares no SUS", ofertado no primeiro semestre do curso de medicina. Dentre as práticas vivenciadas a TCl chamou atenção, por ser genuinamente nordestina, criada com base nas demandas da comunidade, valorizando a cultura e autonomia dos sujeitos.

Após conceituação, iniciou-se a roda de $\mathrm{TCl}$ com o acolhimento. Voluntariamente inquietações, anseios e sofrimentos foram partilhados. Posteriormente, o tema a ser trabalhado foi escolhido, seguido da contextualização e problematização, conforme condução da terapeuta. Um discente relatou seus sofrimentos relativos a migração para ingressar na universidade, estimulando outros a partilharem situações e estratégias adotadas para seus enfrentamentos, por fim houve o encerramento e avaliação da vivência.

A experiência foi significativa, considerando que muitos discentes eram migrantes enfrentando os desafios do distanciamento familiar, da terra de origem, das perspectivas de enfrentar um curso de matriz curricular densa e extensa como o de medicina. Servindo como espaço de apoio, escuta livre sem críticas ou julgamentos, porém, sobretudo, como instrumento imprescindível para a formação de profissionais com olhar crítico, empático e humanizado.

\section{CONSIDERAÇÕES FINAIS}


A abordagem da TCI na educação médica permite momentos de partilha, escuta e construção de vínculos, essenciais tanto na trajetória acadêmica quanto posteriormente na prática médica ampliada. Há que se pensar na prestação do cuidado de forma integral e horizontalizada, ressignificando e fortalecendo a relação médico-paciente, estabelecendo novos paradigmas na atenção em saúde, que perpassam os cuidados clínicos, englobando a intersubjetividade humana a partir da valorização do sensível.

\section{REFERÊNCIAS}

1. BRASIL. Portaria 849 do Ministério da Saúde. 2017. Disponível em: http://bvsms.saude.gov.br/bvs/saudelegis/gm/2017/prt0849_28_03_2017.html. Acessado em: 09 de outubro de 2020.

2. CLIMACO LCC, et al. Conhecendo as práticas integrativas e complementares em saúde: oficina educativa. Rev. enferm UFPE online, 2019; 13(4): 1167-72.

3. NASCIMENTO MVN, OLIVEIRA IF. Práticas integrativas e complementares grupais e o diálogo com a educação popular. Psicologia em pesquisa, 2017; (11): 89-97.

4. TEIXEIRA MZ. Panorama mundial da educação médica em terapêuticas não convencionais (homeopatia e acupuntura). Rev. homeopatia, 2017; 80(1/2): 16-26. 
RESUMO SIMPLES: Revisão Bibliográfica

Título: Efeitos do Ginkgo biloba em pacientes com Acidente Vascular Encefálico: uma revisão integrativa

Autores/coautores: Leonardo Vinícius de Brito Oliveira1; Sérgio Guilherme de Pina Dias'; Lucas Emanuel Carvalho Cavalcante'; Thiago Vinícius Gomes de Oliveira'; Amanda de Figueirôa Silva².

Instituição: 1. Discente da Universidade Federal de Pernambuco (UFPE) Caruaru-Pernambuco; 2. Docente da Universidade Federal de Pernambuco (UFPE) Caruaru-Pernambuco.

Financiamento: Declaramos não ter recebido nenhum tipo de financiamento para a realização dessa pesquisa.

Palavras-Chave: Ginkgo biloba; Acidente Vascular Encefálico; Terapêutica.

\section{INTRODUÇÃO}

O acidente vascular encefálico (AVE) é responsável por parcela considerável de mortes e incapacidade no mundo. Além de ser uma doença de elevada mortalidade, deixa sequelas nos sobreviventes, que podem experimentar declínio neurofuncional, cognitivo e outros desfechos ominosos (CAMPBELL BCV, et al., 2019). O extrato de Ginkgo biloba (GBE) é utilizado no oriente para tratamento adjuvante de distúrbios da memória, depressão e confusão mental e existem evidências teóricas de benefícios cardiovasculares com a utilização do extrato (TIAN J, et al., 2017). A pesquisa dos efeitos a curto e longo prazo do GBE em pacientes vítimas de AVE vêm ganhando posição na literatura científica.

\section{OBJETIVO}

Descrever os efeitos do GBE em pacientes com AVE. Discutir as repercussões do GBE tanto no tratamento inicial do AVE agudo, quanto no desfecho neurofuncional e cognitivo dos pacientes sobreviventes.

\section{MÉTODO}

Revisão integrativa, com pesquisa bibliográfica nas bases MEDLINE/PubMed, EMBASE e SCOPUS. Na estratégia de busca, utilizou-se os descritores "ginkgo biloba", "stroke", "Cerebrovascular Accident" e operadores booleanos OR e AND. Incluímos ensaios clínicos em humanos, revisões sistemáticas ou metanálises congruentes com o tema e excluímos estudos de outras naturezas ou que não se adequaram ao tema pelos títulos e resumos. Dos 87 artigos encontrados, 15 enquadraram-se nos critérios.

\section{REVISÃO BIBLIOGRÁFICA}

O GBE mostrou-se potencialmente eficaz no retardo do declínio neurocognitivo em pacientes vítimas de um AVE agudo. Houve benefícios cognitivos do uso do GBE e a incidência de efeitos colaterais clinicamente relevantes foi desprezível, sendo a via subcutânea a mais eficaz nos efeitos. Um maior desfecho funcional e bem-estar nas atividades diárias em pacientes pós-AVE agudo que utilizaram GBE foi evidenciado, no entanto, sem impacto na mortalidade por todas as causas (CHONG PZ, et al., 2020 e LI S, et al., 2017). Alguns trabalhos sugeriram maior incidência de episódios hemorrágicos em pacientes de alto risco, porém isso foi descartado por revisão sistemática. As propriedades antitrombóticas, anti-inflamatórias, capazes de diminuir a apoptose celular e aumentar o fluxo sanguíneo cerebral (TIAN J, et al., 2017) são as principais hipóteses teóricas da neuroproteção provocada pelo GBE e podem explicar os resultados clínicos obtidos. 


\section{CONSIDERAÇÕES FINAIS}

Apesar de evidências sugerirem que o GBE reduz a velocidade do declínio cognitivo e neurofuncional em vítimas de AVE agudo, os estudos atuais não fornecem fundamentos suficientes para apoiar seu uso rotineiro em pacientes pós-derrame. Mais estudos são necessários com o objetivo de avaliar o efeito do GBE no tratamento e no prognóstico de pacientes com AVE agudo.

\section{REFERÊNCIAS}

1. CAMPBELL BCV. et al. Ischaemic stroke. Nature Reviews Disease Primers, 2019: v. 5, n. 1, p. 1-11, 10 out. 2019.

2. CHONG PZ, et al. Efficacy and Safety of Ginkgo biloba in Patients with Acute Ischemic Stroke: a systematic review and meta-analysis. The American Journal Of Chinese Medicine, v. 48, n. 03, p. 513534, jan. 2020.

3. LI S, et al. Ginkgo biloba extract improved cognitive and neurological functions of acute ischaemic stroke: a randomised controlled trial. Stroke And Vascular Neurology, v. 2, n. 4, p. 189-197, dez. 2017.

4. TIAN J, et al. Ginkgo biloba Extract in Vascular Protection: molecular mechanisms and clinical applications. Current Vascular Pharmacology, v. 15, n. 6, p. 532-548, 28 set. 2017. 
RESUMO SIMPLES: Revisão Bibliográfica

Título: A aplicação da Medicina Tradicional Chinesa no manejo da COVID-19

Autor/coautores: Rafael Cícero de Lima e Silva ${ }^{1}$; Evellyn Beatriz Ferreira Gomes'; lasmine Andreza Basílio de Alves ${ }^{1}$; Samuel Nobre de Miranda'; William Alves Bueno².

Instituição: Universidade Federal de Pernambuco (UFPE), Caruaru - Pernambuco'; Universidade Federal de São João del-Rei (UFSJ), Divinópolis-Minas Gerais².

Palavras-chave: Medicina Tradicional Chinesa; COVID-19; Coronavirus.

\section{INTRODUÇÃO}

A COVID-19 é uma doença causada pelo SARS-CoV-2, vírus do gênero Betacoronavirus com RNA de fita simples. Um surto dessa doença começou na China onde o protocolo de tratamento enfatiza a combinação de Medicina Tradicional Chinesa (MTC) com terapia convencional. A MTC combina filosofia e controle de doenças antigas e tratamentos com eficácia comprovada para diferentes patologias. O conceito geral e os métodos de tratamento são baseados na diferenciação da síndrome, que é a característica mais significativa e essencial (HUANG F, et al., 2020; HUANG YF, et al., 2020).

\section{OBJETIVO}

Revisar a literatura científica na busca de estudos que abordam o manejo e o tratamento de pacientes diagnosticados com COVID-19 através da Medicina Tradicional Chinesa e que demonstrem a eficácia ou não dessa terapia.

\section{MÉTODO}

Trata-se de revisão integrativa da literatura realizada nas bases de dados ScienceDirect e Pubmed. A busca utilizou os termos "traditional chinese medicine" AND "SARS". Os critérios de inclusão da pesquisa: artigos em inglês e português, publicados entre janeiro e setembro de 2020 nas modalidades artigos originais ou de revisão. Foram excluídos relatos de caso, artigos de opinião e artigos incompletos ou publicados fora do período delimitado pelos autores.

\section{REVISÃO BIBLIOGRÁFICA}

Na China, os Medicamentos Chineses (MCs), fitoterápicos fundamentados na MTC, são estratégia para a prevenção e tratamento de COVID-19 em diferentes estágios (HUANG F, et al., 2020).

Dentre os MCs mais usados para a COVID-19 no país, diferenciados em decocções, cápsulas ou injeções de ervas determinadas, tiveram ênfase especial pelo China State Drug Administration a cápsula de Lianhua Qingwen e os grânulos de Huashi Baidu pelo notável alívio sintomático além da diminuição do tempo de reabilitação e da taxa de transferência de casos leves para graves (HUANG YF, et al., 2020; WANG WY, et al., 2020).

Os compostos ativos são direcionados a alvos virais ou do hospedeiro, dessa forma os MCs podem tratar COVID-19 ao direcionar a ligação a proteínas Spike, ACE2, 3CLpro, PLpro e RdRp por docking molecular, 
com foco em seis compostos: quercetina, andrographolide, ácido glicirrízico, baicalina, álcool de patchouli e luteolina (HUANG F, et al., 2020).

\section{CONSIDERAÇÕES FINAIS}

Atualmente, prioriza-se controlar a propagação da COVID-19 e reduzir as taxas de morbimortalidade. Ainda não existe um tratamento específico para COVID-19. São usados tratamentos antivirais de amplo espectro. Assim, a MTC engloba antivirais eficazes contra a COVID-19 que são medicamentos testados in vivo, com baixa toxicidade e biodisponibilidade alta.

\section{REFERÊNCIAS}

1. HUANG F, et al. A review of therapeutic agents and Chinese herbal medicines against SARS-COV-2 (COVID-19). Pharmacological Research, 2020; 158: e104929.

2. HUANG YF, et al. Review on the potential action mechanisms of Chinese medicines in treating Coronavirus Disease 2019 (COVID-19). Pharmacological Research, 2020; 158: e104939.

3. WANG WY, et al. Contribution of traditional Chinese medicine to the treatment of COVID-19. Phytomedicine, 2020: e153279. 
RESUMO SIMPLES: Estudo Original

Título: As Práticas Integrativas e Complementares como dispositivo no cuidado de si de mulheres vítimas de violência: uma perspectiva da Terapia Ocupacional

Autor/Coautores: Rayssa Mesquita da Costa, Dra. Erica de Nazaré Marçal Elmescany.

Instituição: Universidade do Estado do Pará (UEPA), Belém-Pará.

Palavras-chave: Violência, Práticas Integrativas e Complementares, Terapia Ocupacional.

\section{INTRODUÇÃO}

As mulheres sofrem diversas opressões socialmente por meio do controle do corpo e da sexualidade, da violência sexual e psicológica, geralmente ocasionada por pessoas próximas (SOUSA MO e SIRELLI PM, 2018). Consequentemente, sentimento de culpa, vergonha e medo tornam-se recorrentes e, doravante, a autoimagem, autoestima, autoconfiança e o engajamento nas ocupações são fragilizados (GUIMARÃES R, et al., 2018). Portanto, a participação dessas mulheres em grupos da Terapia Ocupacional utilizando as Práticas Integrativas e Complementares (PICS) favorece o resgate da autonomia necessária para desempenhar as ocupações e o fortalecimento da rede de apoio, pois nessas abordagens também recebem suporte de outras mulheres que passaram por situações semelhantes (LIBERMAN F, et al., 2017).

\section{OBJETIVO}

Discutir como as Práticas Integrativas podem ser dispositivos no cuidado de si; compreender a perspectiva de atuação da Terapia Ocupacional, através das Práticas Integrativas e Complementares, na assistência a mulheres vítimas de violência.

\section{MÉTODO}

Trata-se de uma pesquisa-intervenção, baseada no grupo de atividades como recurso para coletar dadosumEAS do bairro Marco. Participaram 4 mulheres vítimas de violência, idade entre 19-49 anos, atendidas no Centro de Referência Especializado de Assistência Social. Realizaram 5 encontros utilizando PICS como meditação, arteterapia e bioenergética. Os dados foram interpretados através da Análise de Conteúdo das falas das participantes. Número do Certificado de Apresentação para Apreciação Ética (CAAE): 11914719.6.0000.5174.

\section{RESULTADOS}

As atividades realizadas no grupo de Terapia Ocupacional, utilizando as Práticas Integrativas e Complementares como recurso terapêutico, mostraram-se como uma significativa forma de intervenção realizadas com mulheres vítimas de violência, pois um espaço de escuta, confiável e potente foi proporcionado a elas e mostrou-se como um impulso inicial para um processo de autoconhecimento, a partir das experiências proporcionadas pelas Práticas Integrativas e Complementares utilizadas. Além disso, elas favoreceram o autocuidado, proporcionaram um contato consigo e uma autopercepção profunda e resgataram um aspecto fundamental para que haja uma motivação para cuidar de si: a autoestima.

\section{CONSIDERAÇÕES FINAIS}


Deste modo, esta pesquisa corroborou a importância da atuação do terapeuta ocupacional na assistência às mulheres vítimas de violência, por meio de atividades que utilizam as Práticas Integrativas e Complementares como recurso, as quais possibilitam a ressignificação das marcas visíveis e invisíveis na corporeidade e a reinserção social.

\section{REFERÊNCIAS}

1. GUIMARÃES R, et al. Impacto na autoestima de mulheres em situação de violência doméstica atendidas em Campina Grande. Revista Cuidarte, 2018; 9(1): 1988-1997.

2. LIBERMAN F, et al. Práticas corporais e artísticas: aprendizagem inventiva e cuidado de si. Fractal: Revista de Psicologia, 2017; 29(2): 118-126.

3. SOUSA MO, SIRELLI PM. Nem santa, nem pecadora: novas roupagens, velhas dicotomias na coisificação da mulher. Revista Serviço Social \& Sociedade, 2018; (132): 326-345. 
RESUMO SIMPLES: Relato de Experiência

Título: Meditação na formação médica: um relato de experiência

Autor/coautores: Ângela Reis Teixeira, Thanilly Silveira Macedo, Júlio Samuel Silva Souza, Daniel Bastos Alves Lima, Patrícia Baier Krepsky.

Instituição: Universidade Federal da Bahia (UFBA. Vitória da Conquista - Bahia.

Palavras-chave: Práticas Integrativas e Complementares, Meditação, Integralidade em Saúde.

\section{INTRODUÇÃO}

Dez anos após a implantação da Política Nacional de Práticas Integrativas e Complementares (PNPICS) do Sistema Único de Saúde (SUS), a meditação foi inserida no escopo de serviços ofertados à população (BRASIL, 2017). Caracterizada como um conjunto de técnicas que estimulam o foco e atenção, a meditação é capaz de proporcionar uma integração entre corpo e mente, promovendo a concentração, auxiliando na percepção sobre as sensações físicas e emocionais, ampliando a autodisciplina no cuidado à saúde (TELESI JÚNIOR ET, 2016). Estudos evidenciam que a meditação promove variações nos níveis de cortisol, reduzindo o estresse, além de alterações neurofisiológicas, promovendo saúde, bem-estar e qualidade de vida (MEDEIROS AM, 2017).

\section{OBJETIVO}

Relatar a experiência dos estudantes de medicina de uma universidade da Bahia, no componente intitulado "Práticas Integrativas e Complementares do SUS", destacando os benefícios da inserção das práticas integrativas no processo de formação.

\section{RELATO DE EXPERIÊNCIA}

A prática da meditação foi realizada em um componente curricular do primeiro semestre do curso de medicina, possibilitando um primeiro contato com as Práticas Integrativas e Complementares (PICS). Na primeira etapa da vivência foram explanados aspectos teóricos da meditação e sua aplicabilidade nos serviços de saúde, comprovando que esta prática milenar se faz presente em diversas culturas promovendo o bem estar físico, mental, emocional e social.

$\mathrm{Na}$ segunda etapa realizou-se a meditação conduzida por um profissional da área. Seguindo suas orientações, ao som do sino tibetano, todos em posição confortável, de olhos fechados, corpos relaxados, controlando a respiração na tentativa de elevar a concentração e acalmar corpo e mente. Ao final, foram partilhadas as experiências através de uma roda de conversa, na qual percebeu-se que a meditação constitui uma maneira simples e eficaz de estimular o foco, o relaxamento e equilíbrio psíquico e físico. Além disso, salientou-se a importância das PICS nas práticas de saúde e na formação de futuros profissionais capacitados para atender de forma integral as demandas da população.

\section{CONSIDERAÇÕES FINAIS}

Contudo, a ampliação das PICS no campo das ciências psicofísicas ressignifica o cuidado integral à saúde, bem como contribui para fortalecimento do SUS. A prática da meditação, além de restabelecer o equilíbrio, 
auxilia na busca pela identificação e reafirmação do indivíduo com sua própria essência, voltando o olhar dos futuros profissionais médicos para novas formas de fazer saúde.

\section{REFERÊNCIAS}

1. BRASIL. Ministério da Saúde. Gabinete do Ministro. Portaria no 849, de 27 de março de 2017. Inclui a Arteterapia, Ayurveda, Biodança, Dança Circular, Meditação, Musicoterapia, Naturopatia, Osteopatia, Quiropraxia, Reflexoterapia, Reiki, Shantala. Disponível em: http://bvsms.saude.gov.br/bvs/saudelegis/gm/2017/prt0849_28_03_2017.html Acesso em: 14 de out. 2020

2. MEDEIROS, AM. Práticas integrativas e complementares no SUS: os benefícios do Yoga e da Meditação para a saúde do corpo e da alma. Revista Eletrônica Correlatio, 2017; 16(2).

3. TELESI JÚNIOR, E. Práticas integrativas e complementares em saúde, uma nova eficácia para o SUS. Estud. av. 2016; 30(86). 
RESUMO SIMPLES: Revisão Bibliográfica

Título: O impacto do Tai Chi Chuan na Hipertensão Arterial Sistêmica Essencial: uma revisão narrativa

Autor/coautores: Josiane de Lima Balbino dos Santos ${ }^{1}$, Laís Pedroso Tagliari ${ }^{1}$, Ludmilla Ferreira Aragão ${ }^{1}$, Andesson Silva dos Santos ${ }^{1}$ e Vanessa Bruna Alves Pereira Curzio².

Instituição: Universidade Estácio de Sá (UNESA), Rio de Janeiro-Rio de Janeiro; Universidade Federal do Rio de Janeiro (UFRJ), Rio de Janeiro-Rio de Janeiro².

Palavras-chave: Terapias Complementares; Tai Chi Chuan; Hipertensão.

\section{INTRODUÇÃO}

A Hipertensão Arterial Sistêmica (HAS) é uma das doenças crônicas de maior prevalência a nível mundial. A forma mais prevalente (primária) está estritamente relacionada com o estilo de vida do paciente. Assim, nutrição saudável, não exposição a fatores de risco cardiovasculares como tabaco e prática de atividades físicas são peças fundamentais no manejo desta doença (GUAN Y, et al., 2020). Nesse contexto, o Tai Chi Chuan (TCC) - prática integrativa e complementar em saúde que trabalha corpo e mente através da realização de movimentos suaves e controle da respiração - pode ser um aliado no controle da pressão arterial (PA) de hipertensos (ZHONG D, et al., 2020).

\section{OBJETIVO}

Analisar o impacto da prática do Tai Chi Chuan no manejo da Hipertensão Arterial Sistêmica primária (ou essencial) por meio da realização de uma revisão narrativa da literatura científica disponível acerca da temática.

\section{REVISÃO BIBLIOGRÁFICA}

A análise do comportamento da PA e do duplo produto (DP) de idosos com HAS antes e após uma sessão de TCC evidenciou queda significativa da PA média no $10^{\circ}$ minuto após a sessão, da PA sistólica (PAS) no $20^{\circ}$ e da PA diastólica (PAD) no $60^{\circ}$. Em comparação aos valores pré-exercício a redução foi de $22 \mathrm{mmHg}$ para PAS e $18 \mathrm{mmHg}$ para PAD. Houve diminuição do DP do minuto 30 aos 60 pós atividade. Os dados sugerem alto potencial hipotensor do TCC após uma única prática (CARVALHO R, et al., 2017).

Em pacientes jovens e de meia-idade, com HAS grau 1, houve importante redução dos níveis pressóricos após três meses de TCC: $13 \mathrm{mmHg}$ na PAS; $7 \mathrm{mmHg}$ na PAD. Ademais, foi demonstrada melhora do perfil lipídico, glicemia e redução da frequência cardíaca e índice de massa corporal (SHOU X, et al., 2019).

Foi observada também maior redução da PA e melhora psicossocial se comparado às caminhadas rápidas (SMITH GD, 2019).

\section{CONSIDERAÇÕES FINAIS}

Os estudos sugerem fortemente impacto significativo do TCC na redução da PA de pacientes com HAS primária, associada a redução da frequência cardíaca. Além disso, demonstrou interferir minimizando fatores de risco cardiovasculares diminuindo o risco desses pacientes com relação aos desfechos cardiovasculares. 
Desse modo, propõe-se que a prática do TCC seja proposta como tratamento não farmacológico na HAS primária pelo seu potencial benefício no manejo desta doença.

\section{REFERÊNCIAS}

1. CARVALHO R, et al. Sessão de Tai Chi Chuan promove hipotensão pós-exercício e redução da sobrecarga cardiovascular em idosos hipertensos. Medicina (Ribeirão Preto), 2017; 50(5): 297-306.

2. GUAN Y, et al. Effects of Tai Chi on essential hypertension and related risk factors: A meta-analysis of randomized controlled trials. Journal of Rehabilitation Medicine, 2020; 52(5): jrm00057.

3. SHOU X, et al. Effect of Tai Chi Exercise on Hypertension in Young and Middle-Aged In-Service Staff. The Journal of Alternative and Complementary Medicine, 2019; 25(1): 73-78.

4. SMITH GD. Tai Chi: a promising adjunct nursing intervention to reduce risks of cardiovascular disease and improve psychosocial well-being in adults with hypertension. Evid Based Nurs, 2019; 22(2):45.

5. ZHONG D, et al. Tai Chi for Essential Hypertension: a Systematic Review of Randomized Controlled Trials. Current Hypertension Reports, 2020; 22(3):25. 
RESUMO SIMPLES: Relato de Experiência

Título: Projeto "Acolhendo Quem Cuida": Oferta da terapia mesa radiônica via remota em tempos de pandemia

Autor/coautores: Giovanny Santos Silva / Karla Natally Santos, Larissa Santos Oliveira, Alicia de Sousa Lisboa e Adriana Andrade Carvalho.

Instituição: Universidade Federal de Sergipe (UFS), Lagarto/Sergipe.

Palavras-chave: Radiônica, Radiestesia, Vibracional.

\section{INTRODUÇÃO}

A Mesa Radiônica, terapia integrativa e complementar, tem o efeito de identificar, perceber e sentir alterações energéticas corporais, dessa forma a cura vibracional é realizada com ajuda de um pêndulo e cristais. Sendo assim, alterações energéticas podem ser identificadas através dessa terapia. Ela contribui de forma positiva para acolher a população, aumentando o bem-estar e ajudando no controle emocional, auxiliando em diversas desordens. Com isso, docentes e discentes de uma instituição de ensino no Nordeste, com o intuito de acolher a população neste momento difícil, tiveram a iniciativa de ofertar a terapia Mesa Radiônica, dentre outras, via plataformas online.

\section{OBJETIVO}

Relatar a experiência vivenciada no Projeto "Acolhendo Quem Cuida" (AQC) de uma instituição de ensino superior, a partir da oferta de atendimento da terapia Mesa Radiônica via remota, em tempos de pandemia.

\section{RELATO DE EXPERIÊNCIA}

Trata-se de um projeto de extensão composto por docentes e discentes de uma instituição no Nordeste, o qual oferta terapias integrativas e complementares, via plataformas online, ao público. São oferecidas 7 terapias, dentre elas a Mesa Radiônica. A solicitação é feita por um formulário do Google encontrado nas redes sociais do projeto, onde o indivíduo informa dados pessoais, principais queixas e terapia escolhida. Desde o início do projeto, no mês de abril, até o mês de outubro foram realizados mais de 100 atendimentos dessa terapia, incluindo consultas de retorno. Dentre as ofertas a Mesa Radiônica está entre as mais procuradas, com $29,4 \%$ dos pedidos no formulário.

No início do projeto as principais queixas relatadas foram medo e ansiedade relacionada a pandemia e dificuldades de relacionamentos interpessoais, cujo afetou áreas socias, profissionais e pessoais. Observouse uma maior prevalência em dificuldades de ter foco nas atividades diárias, rememoração do passado, maior vontade em buscar espiritualidade e propósito de vida. Após o tratamento as principais sensações foram leveza, tranquilidade e bem-estar.

\section{CONSIDERAÇÕES FINAIS}

A oferta da Mesa Radiônica via remota tem sido extremamente satisfatória e as pessoas têm relatado melhora sutil de suas atitudes/comportamentos em desequilíbrio, inclusive retornos estão sendo procurados para complementar o tratamento das queixas relatadas inicialmente, como também, de outras queixas 
secundárias. Essa iniciativa está contribuindo positivamente para o enfrentamento de um problema que atinge a saúde física e mental, como os aspectos sociais, financeiros e familiares.

\section{REFERÊNCIAS}

1. ARIANA P. Avaliação do uso da radiestesia como ferramenta de diagnóstico na clínica de pequenos animais. Centro de Ciências Agrárias Ambientais e Biológicas, 2017; 1:12.

2. EMÍLIO J. Práticas integrativas e complementares em saúde, uma nova eficácia para o SUS. Revista Estudos Avançados, 2016; 99-112.

3. JOSÉ M. Efeito da terapia vibracional por biocomunicação instrumental sobre fatores de risco da doença arterial coronariana e modulação da frequência cardíaca. Programa de Pós-Graduação em Desenvolvimento Humano e Tecnologias, 2017; 1: 1-4. 
RESUMO SIMPLES: Revisão Bibliográfica

Título: A utilização da acupuntura auricular no tratamento da dor lombar em gestantes de risco habitual

Autor/coautores: Letícia Mayara da Silva, Ingryd Maria Tenório da Silva, Luan Maurício de Lima, Leticia Rafaele Figueirôa de Melo Dias, Gêssyca Adryene de Menezes Silva

Instituição: Centro Universitário Tabosa de Almeida (ASCES-UNITA), Caruaru-Pernambuco.

Palavras-chave: Acupuntura, Lombalgia, Gestação.

\section{INTRODUÇÃO}

A lombalgia é caracterizada por dores na região lombar, apresentando sintomas incapacitantes, e em sua maioria acomete mais pessoas do gênero feminino, principalmente durante a gravidez (MARTINS ES, et al., 2019). Ao longo do período gestacional, a Dor Lombar (DL) pode ser aliviada através de fármacos, porém há limitação quanto ao uso de uma gama de analgésicos por apresentar consequências para a mãe e o feto. É nesse cenário que as Práticas Integrativas e Complementares (PICS) surgem, pois há a procura principalmente da acupuntura, para o tratamento não farmacológico da DL (MARTINS ES, et al., 2018).

\section{OBJETIVO}

Revisar as literaturas científicas que buscam avaliar a utilização da acupuntura auricular no tratamento da dor lombar em gestantes no segundo e terceiro trimestre de gestação que realizam consultas de pré-natal de risco habitual.

\section{MÉTODO}

Revisão bibliográfica integrativa com artigos encontrados nas bases de dados BDENF, LILACS e MEDLINE, utilizando os descritores: acupuntura auricular, dor lombar, gravidez, cruzados com o operador booleano AND. Foram adotados como critérios de inclusão: artigos em português, inglês e espanhol, publicados entre 2018-2020. Foram encontrados 9 artigos, após a leitura dos resumos, 6 estudos foram excluídos por ser literatura duplicada nas bases de dados, ou estudos que não se adequaram a temática proposta, uma vez que este foi o critério de exclusão estipulado.

\section{REVISÃO BIBLIOGRÁFICA}

A acupuntura é uma prática da Medicina Tradicional Chinesa (MTC) que tem como objetivo a promoção da cura através da estimulação do equilíbrio energético corporal (MARTINS ES, et al., 2018). Por haver poucas contraindicações, esta é utilizada, nesse caso, baseada em um protocolo para DL em gestantes, a fim de tratar e promover bem-estar.

A acupuntura auricular mostrou reduzir significativamente a DL e a dor pélvica em mulheres grávidas, proporcionando melhor qualidade de vida e capacidade funcional (VAS J, et al., 2019). O impacto considerável do desconforto causado pela lombalgia na gestante, foi amenizado após a realização da acupuntura sistêmica e auricular, concomitantes, nas participantes do estudo de Martins e colaboradores em 2019. A redução da intensidade da dor foi obtida ao final do tratamento, onde a acupuntura se apresentou nove vezes mais eficaz se comparado aos cuidados obstétricos padrão (VAS J, et al., 2019). 


\section{CONSIDERAÇÕES FINAIS}

A utilização da acupuntura auricular em situações de DL em gestantes, entre 14 e 37 semanas, se apresentou significativa, promovendo saúde e qualidade de vida, entretanto ficou evidente que se associada com a acupuntura sistêmica, o tratamento apresenta resultados mais intensos.

\section{REFERÊNCIAS}

1. MARTINS ES, et al. Enfermagem e a prática avançada da acupuntura para alívio da lombalgia gestacional. Acta Paulista de Enfermagem, [S.L.], 2019; 32(5), 477-484.

2. MARTINS ES, et al. Tratamento com acupuntura: avaliação multidimensional da dor lombar em gestantes. Revista da Escola de Enfermagem da Usp, [S.L.], 2018; 52, 1-1, 11.

3. VAS J, et al. Effect of ear acupuncture on pregnancy-related pain in the lower back and posterior pelvic girdle: a multicenter randomized clinical trial. Acta Obstetricia Et Gynecologica Scandinavica, [S.L.], 2019; 98(10), 1307-1317. 
RESUMO SIMPLES: Revisão Bibliográfica

Título: Eficácia da musicoterapia no tratamento do transtorno do espectro autista: uma revisão integrativa

Autor/coautores: Luana Caroline Dinelli Oliveira Duque'; Giovanna Adriany Melo de Goes², Matheus Pereira de Araújo²; Beatriz Pereira da Silva²; Sebastião Pacheco Duque Neto³.

Instituição: 'Universidade Estácio de Sá (UNESA) Alagoinhas-Bahia; 2Universidade Federal de Pernambuco (UFPE), Caruaru-Pernambuco; ${ }^{3}$ Universidade Federal do Rio Grande do Norte (UFRN), Caicó- Rio Grande do Norte.

Palavras-chave: Musicoterapia, Espectro Autista, Crianças.

\section{INTRODUÇÃO}

O transtorno do espectro autista (TEA) é uma síndrome comportamental que acomete o sistema motor, neural, psicológico e a cognição do indivíduo, dificultando, portanto, suas relações interpessoais (PINTO RNM, et al., 2016). Sua etiologia é desconhecida, podendo ser considerada multicausal, influenciada por fatores genéticos, neurológicos e/ou sociais (PINTO RNM, et al., 2016). Sem cura definitiva, os tratamentos têm como objetivo amenizar a sintomatologia, ampliando as habilidades verbal e não verbal, o ciclo de interesses e a interatividade socia. A musicoterapia, através das Práticas Integrativas, vem sendo utilizada como mais uma alternativa de tratamento (FERNANDES PRS, 2016). Dessa forma, é relevante buscar na literatura evidências para a utilização da musicoterapia no tratamento desses pacientes.

\section{OBJETIVO}

Sistematizar conhecimentos, por meio da revisão literária, a respeito dos benefícios da musicoterapia e quais mudanças podem ser promovidas em cada aspecto da vida do paciente com transtorno do espectro autista.

\section{MÉTODO}

Essa revisão integrativa foi realizada no mês de outubro de 2020 por meio das bases de dados Scielo, Pubmed/MEDLINE e BVS, com a utilização dos seguintes descritores "Music Therapy", "Autism disorder". Os critérios de inclusão foram: estudos publicados em inglês ou português, entre os anos de 2010-2020. Enquanto os de exclusão foram aqueles que não abordavam o TEA, não discutiam o tratamento por meio da musicoterapia ou que foram escritos em período diferente do selecionado.

\section{REVISÃO BIBLIOGRÁFICA}

No presente estudo foi observado que são poucos os ensaios clínicos randomizados que inferem sobre os benefícios da musicoterapia no tratamento de crianças com TEA. No entanto, todos os estudos selecionados por essa revisão confirmam que a prática musicoterapêutica, possui a capacidade de atingir diferentes regiões do cérebro de uma maneira não aversiva, o que pode ser consequência de sua ação sobre as conexões de circuitos neurais envolvidos com a emoção e cognição do indivíduo. A Musicoterapia Criativa, por exemplo, objetiva desenvolver a criatividade do indivíduo de maneira ativa e exigir a criatividade musical do musicoterapeuta para ampliar o fazer musical do paciente e atingir os objetivos terapêuticos traçados, o que promove processos cognitivos complexos, processamentos emocionais, interações sociais, memória, planejamento e controle de impulsos em pessoas com TEA (SAMPAIO RT, et al., 2015). 


\section{CONSIDERAÇÕES FINAIS}

Pode-se observar que a musicoterapia para crianças com TEA melhorou sua interação social recíproca, comunicação, imaginação e leque de interesses. Todavia, é necessário que haja mais estudos sobre o tema, para subsidiar novas abordagens de tratamento e avaliação dessa prática.

\section{REFERÊNCIAS}

1. FERNANDES, P.R.S. Musicoterapia e Pertubação do Espetro do Autismo. Journal of Research in Special Educational Needs, Braga, 2016, 16(1), 725-730.

2. PINTO RNM, et al. Autismo infantil: impacto do diagnóstico e repercussões nas relações familiares. Revista Gaúcha de Enfermagem, 2016; 37(3), 2.

3. SAMPAIO RT, et al. A Musicoterapia e o Transtorno do Espectro do Autismo: uma abordagem informada pelas neurociências para a prática clínica. Escola de música da UFMG, 2015; 1(32), 137-170. 
RESUMO SIMPLES: Relato de Experiência

Título: Trabalho final da disciplina "Práticas Complementares em Saúde" no Ensino Remoto Emergencial: Relato de experiência

Autor/coautores: Gabriele Pimentel Sinimbu; Firmina Hermelinda Saldanha Albuquerque; Dalila de Alcântara Martins; Lucas Pereira da Costa; Thayná Ferreira Albuquerque Gomes.

Instituição: Universidade Federal do Amazonas (UFAM), Manaus-Amazonas.

Palavras-chave: Ensino Remoto Emergencial, Práticas Complementares em Saúde, Enfermagem.

\section{INTRODUÇÃO}

O profissional de enfermagem pode atuar na área de Práticas Integrativas e Complementares em Saúde (PICS), assim, a abordagem desse tema durante a graduação é essencial (ALMEIDA JR, et al., 2018). Contudo, na maioria das universidades, a disciplina sobre PICS é ofertada de forma optativa, quando há essa possibilidade, e conduz ao aprendizado sobre o histórico das diversas PICS, com ênfase nas regulamentadas pelo Sistema Único de Saúde (DORNELES FC, et al., 2020; AZEVEDO C, et al., 2019). Em 2020, a pandemia de COVID-19 afetou diversos setores, incluindo o de ensino, e algumas universidades optaram pelo ensino remoto como uma forma de possibilitar a continuação da aprendizagem.

\section{OBJETIVO}

Relatar a experiência de acadêmicos da área da saúde durante o Ensino Remoto Emergencial (ERE) na disciplina de Práticas Complementares em Saúde de uma universidade pública da região norte do Brasil.

\section{RELATO DE EXPERIÊNCIA}

A experiência proporcionada pela disciplina pode ser considerada satisfatória. Por tratar-se de um momento atípico, a forma com que a matéria tem sido abordada reforça a sua importância durante o processo de formação na área de saúde. É valido ressaltar que por ser uma experiência e ambientação das aulas no ensino remoto, a organização de discentes e docentes é primordial para o bom andamento da disciplina. É fato que o ERE vem com seus desafios, principalmente por ser transmitida por meio das mídias digitais, com o qual alguns discentes e docentes encontraram dificuldades para adaptar-se, além de que as transmissões também necessitam de uma conexão estável de internet. O ERE traz como pontos positivos a possibilidade da presença de um profissional especialista situado em qualquer lugar do Brasil ou do mundo, pois nesta modalidade não são consideradas as barreiras geográficas, também pode-se elencar como ponto positivo a dinamicidade das aulas e os recursos explorados, como vídeos, animações, formulários e fóruns de discussão online.

\section{CONSIDERAÇÕES FINAIS}

No novo ambiente de aprendizado surgem novos desafios para a docência e aprendizado individual dos alunos, mas também se expande as possibilidades de acesso a profissionais e ferramentas que complementam o conhecimento. Salienta-se a relevância da disciplina no contexto da graduação, visto que 
essa aborda as diversas possibilidades terapêuticas para além do modelo biomédico e contribui para uma formação mais humana e holística do enfermeiro.

\section{REFERÊNCIAS}

1. ALMEIDA JR, et al. O enfermeiro frente às práticas integrativas e complementares em saúde na estratégia de saúde da família. Revista Eletrônica Acervo Saúde, 2018, 18, e77.

2. AZEVEDO C, et al. Práticas integrativas e complementares no âmbito da enfermagem: aspectos legais e panorama acadêmico-assistencial. Escola Anna Nery, 2019, 23(2), e20180389.

3. DORNELES FC, et al. Enfermagem e as Práticas Integrativas e Complementares em saúde: uma revisão Integrativa. Research, Society and Development, 2020, 9(9), e445997446. 
RESUMO SIMPLES: Revisão Bibliográfica

Título: Níveis de evidências dos estudos científicos sobre Reiki no Brasil: uma revisão integrativa

Autor/coautores: Moisés Fiúsa Menezes', Cláudia Maria de Souza Gonçalves', Lucas Thadeu Silva de Ferreira Morais², Maria Olivia de Araújo Pereira1', William Alves Bueno¹.

Instituição: Universidade Federal de São João del-Rei (UFSJ), Divinópolis-Minas Gerais'. Faculdade Pitágoras, Divinópolis-Minas Gerais².

Palavras-chave: Reiki, Saúde Baseada em Evidência, Imposição de Mãos.

\section{INTRODUÇÃO}

O Reiki é uma Prática Integrativa e Complementar em Saúde (PICS) baseada na canalização da energia vital pela imposição de mãos (BRASIL, 2018a). Mesmo sendo difundido e ofertado pelo Sistema Único de Saúde desde 2015, não há consenso sobre suas ações na saúde (BRASIL, 2018b). Portanto, é importante mapear a variedade e qualidade das pesquisas sobre o Reiki no Brasil, através da Saúde Baseada em Evidências (SBE) (BEULKE SL, et al., 2019). A qual hierarquiza os estudos por nível de evidência (NE) conforme desenho e rigor metodológicos numa escala de 1 a 6 . (SCHNEIDER LR, et al., 2018).

\section{OBJETIVO}

Investigar os níveis de evidências científicas das pesquisas produzidas e publicadas no Brasil sobre o Reiki, por meio de uma revisão integrativa de literatura, utilizando os critérios da Saúde Baseada em Evidência.

\section{MÉTODO}

Revisão integrativa norteada pela questão: "as pesquisas sobre Reiki no Brasil possuem adequados níveis de evidência?". Realizou-se a busca em agosto de 2020 pelos descritores Reiki e Imposição de Mãos nas bases: Biblioteca Virtual em Saúde (BVS) e Scientific Eletronic Library Online (Scielo). Inclui-se artigos produzidos e publicados Brasil na íntegra de acesso gratuito, excluiu-se publicações anteriores a 2016. Identificou-se 121 artigos, dos quais 20 constituíram a amostra final.

\section{REVISÃO BIBLIOGRÁFICA}

Apesar do Reiki ser uma prática recomendada para diversos cuidados em saúde, as investigações científicas tinham reduzida abrangência com enforque, principalmente, no controle da dor, estresse e ansiedade $60 \%$ da amostra (LOCATELI G, et al., 2020). Os outros $40 \%$ dos trabalhos abordaram as interações do Reiki na qualidade de vida/sono, controle da pressão arterial, sintomatologia diabética e técnicas de aplicação (ANTUNES PC, et al., 2018).

Conforme o escalonamento por nível de evidências, estudos de meta-analise (NE 1) capazes de produzir generalizações não foram encontrados. Como também, pesquisas com altos NE $(1,2,3)$ representam apenas $20 \%$ da amostra, todos com significativa associação de efeito placebo ( $>30 \%)$. Em contrapartida, $70 \%$ das pesquisas possuem NE baixos $(4,5,6)$, com também $50 \%$ da amostra são estudos de casos (NE 5), fatores que conferem pouca confiabilidade e abrangência sobre a efetividade do Reiki (SCHNEIDER LR, et al., 2018). 


\section{CONSIDERAÇÕES FINAIS}

A revisão demonstrou que os estudos sobre o Reiki no Brasil são escassos e possuem, majoritariamente, baixos NE. Nota-se que as publicações nacionais não possibilitam a comprovação ou refutação da efetividade do Reiki enquanto PICS. Portanto, são necessário estudos com maior rigor metodológico e variedade de abrangência na saúde das pessoas.

\section{REFERÊNCIAS}

1. ANTUNES PC, et al. Revisão sistemática sobre práticas corporais na perspectiva das práticas integrativas e complementares em saúde. Motrivivência, 2018; 30(55): 227-247.

2. BRASIL. Manual de implantação de serviços de práticas integrativas e complementares no SUS. 2018a. Disponível em: https://aps.saude.gov.br/biblioteca/visualizar/MTMONQ. Acessado em: 03 de outubro de 2020.

3. BRASIL. Portaria $n^{\circ} 702$. Altera a portaria de consolidação $n^{\circ}=2 / G M / M S$ para incluir novas práticas na Política Nacional de Práticas Integrativas e Complementares - PNPIC. 2018b. Diponível em: https://bvsms.saude.gov.br/bvs/saudelegis/gm/2018/prt0702_22_03_2018.html . Acessado em: 02 de outubro de 2020.

4. BEULKE SL, et al. Reiki no alívio de sinais de sintomas biopsicoemocionais relacionados à quimioterapia. Cogitare Enfermagem, 2019; 24: e56694.

5. LOCATELI G, et al. Acendendo as luzes: uma inovação no cuidado a saúde dos pacientes oncológicos, Familiares e equipe. Saúde em Redes, 2020; 6(1): 155-162.

6. SCHNEIDER LR, et al. Prática Baseada em Evidência no contexto da Atenção Primária à Saúde. Saúde Debate, 2018; 42(118): 594-605. 
RESUMO SIMPLES: Relato de Experiência

Título: O impacto da formação de uma Liga Acadêmica de Medicina Integrativa no desenvolvimento acadêmico de estudantes de Medicina

Autor/coautores: Josiane de Lima Balbino dos Santos, Laís Pedroso Tagliari, Ludmilla Ferreira de Aragão, Andesson Silva dos Santos e Roberto José Adrião Povoleri Fuchs.

Instituição: Universidade Estácio de Sá (UNESA), Rio de Janeiro-Rio de Janeiro.

Palavras-chave: Liga Acadêmica, Medicina Integrativa, Terapias Complementares.

\section{INTRODUÇÃO}

O modelo biomédico proposto por Flexner ainda exerce grande influência nas escolas médicas (REYES $X P, 2020)$. Aquilo que foge a ele costuma não integrar a grade curricular, como exemplo: as Práticas Integrativas e Complementares em Saúde (PICS). Numa universidade do estado do Rio de Janeiro, a disciplina Psiquiatria não aborda os resultados positivos da meditação (SAEED SA, et al., 2019) ou da homeopatia no manejo dos transtornos de ansiedade (GRIMALDI-BENSOUDA, et al., 2016). A percepção da ausência, em sua universidade, de espaço para abordagem da Medicina Integrativa (MI) e suas ferramentas (as PICS) estimulou uma estudante de Medicina a iniciar a formação de uma Liga Acadêmica referente ao tema.

\section{OBJETIVO}

Relatar o processo de formação de uma Liga Acadêmica de Ml e Complementar em uma universidade privada no estado do Rio de Janeiro e o impacto deste processo no amadurecimento acadêmico de estudantes de medicina.

\section{RELATO DA EXPERIÊNCIA}

Inicialmente formou-se uma equipe de diretoria com mais quatro alunos da instituição. Eles estruturaram os documentos que regeriam a Liga, uma logo representativa e iniciaram a produção de rede social para divulgação da mesma e de conteúdo relacionado às PICS. Para isso, demandou-se uma imersão nas regras para composição de um Estatuto e principalmente em uma revisão bibliográfica para maior entendimento acerca da MI e das PICS.

A Liga teve alta procura: 40 alunos se inscreveram para fazer parte e tornaram-se membros. Considerando que as Ligas da universidade contam, em média, com 20 alunos por semestre, esse índice duas vezes maior evidência a demanda dos estudantes por aprender sobre a temática.

Todo o processo contribuiu para aquisição, nos estudantes de Medicina que ergueram a Liga, de habilidades de pesquisa para aperfeiçoar o entendimento sobre o tema; de comunicação e marketing digital para divulgação; de compreensão da dinâmica de confecção de Currículo Lattes mais atrativo para obtenção de melhor pontuação em provas de Residência Médica e, principalmente, contribuiu com a prática médica ao estimular o trabalho em equipe. 


\section{CONSIDERAÇÕES FINAIS}

A Liga Acadêmica de Medicina Integrativa e Complementar formada objetiva possibilitar que, ao conhecer outras possibilidades de tratamento e promoção de saúde, os alunos possam aplicá-las em sua prática médica futura, ofertando as PICS e exercendo um olhar mais integral para o paciente. O empenho para formação da Liga contribuiu com a formação acadêmica dos estudantes envolvidos ao possibilitar o desenvolvimento de habilidades importantes no meio acadêmico-científico.

\section{REFERÊNCIAS}

1. REYES XP. Revolución Flexneriana y su influencia en la educación médica. Revista Científica de la Escuela Universitaria de las Ciencias de la Salud, 2019; 6(6): 61-72.

2. BENSOUDA-GRIMALDI L, et al. Homeopathic medical practice for anxiety and depression in primary care: the EPI3 cohort study. BMC Complementary and Alternative Medicine, 2016; 16(125): https://doi.org/10.1186/s12906-016-1104-2.

3. SAEED SA, et al. Depression and Anxiety Disorders: Benefits of Exercise, Yoga, and Meditation. American Family Physician, 2019. 99(10): 620-627. 
RESUMO SIMPLES: Revisão Bibliográfica

Título: Práticas integrativas e complementares em saúde: uma realidade no SUS.

Autor/coautores: Alícia Calinne Melo Santos, Ana Caroline Gusmão de Matos, Carmem Isaura Salles do Nascimento, Nathalia Costa Macedo Noronha, Luana Godinho Maynard.

Instituição: Universidade Tiradentes (UNIT), Aracaju - Sergipe.

Palavras-chave: PIC, Medicina complementar, Práticas integrativas.

\section{INTRODUÇÃO}

As Práticas Integrativas e Complementares (PICS) são tratamentos que utilizam recursos terapêuticos baseados em conhecimentos tradicionais, voltados à prevenção de doenças como depressão e hipertensão. Em determinados casos, também podem ser usadas como tratamentos paliativos em algumas doenças crônicas. (BRASIL, 2006). No Brasil, tal prática é reconhecida e incorporada pelo Sistema Único de Saúde (SUS) através da Política Nacional de Práticas Integrativas e Complementares (PNPIC), desde 2006. É uma política intersetorial que atua na Política Nacional de Atenção Básica (PNAB), em conjunto com outras políticas, em situações onde nem sempre o modelo biomédico é suficiente para reduzir os sintomas e prevenir agravos. (FERRAS SI, et al., 2020).

\section{OBJETIVO}

Realizar uma revisão de literatura sobre as práticas integrativas e complementares em saúde no Brasil, o que hoje já é uma realidade proporcionada pelo Sistema Único de Saúde (SUS).

\section{MÉTODO}

Trata-se de uma revisão de literatura baseada em artigos de revisão bibliográfica e sistemática com metanálise publicados entre 2019 e 2020, em língua inglesa, portuguesa e espanhola na base de dados Scielo. Foram identificados 35 estudos, através dos descritores: medicina integrativa; PIC e medicina complementar, filtrados entre 2019 e 2020. Desses foram selecionados 15, dentre os quais 7 foram incluídos neste trabalho por apresentarem resultados que respondem aos objetivos deste.

\section{REVISÃO BIBLIOGRÁFICA}

As Práticas Integrativas Complementares visam reorganizar os níveis de atenção e a auxiliar na implementação de novas técnicas de cuidado no âmbito do SUS (FERRAZ IS, et al., 2020). A Política Nacional de Práticas Integrativas e Complementares, por sua vez, busca garantir a necessidade de conhecer, apoiar e incorporar a atuação das PIC já em andamento, buscando estimular os mecanismos naturais de prevenção, recuperação e promoção da saúde com ênfase na Atenção Primária. (BRASIL. Ministério da Saúde). Para tanto, destaca-se a criação do Núcleo de Apoio a Saúde da Família (NASF) que viabiliza a inserção de profissionais médicos homeopatas e acupunturistas, bem como outros profissionais praticantes de PIC no âmbito da Atenção Básica (HABIMORAD PHL, et al., 2020). No entanto, alguns desafios precisam ser vencidos para dar continuidade à inserção dessa política na saúde pública, como a viabilização da formação e qualificação dos profissionais em número adequado para atuar no Sistema Único de Saúde. 


\section{CONSIDERAÇÕES FINAIS}

A implantação das PIC no SUS, portanto, configura uma ação de ampliação de acesso e qualificação dos serviços na perspectiva da integralidade da atenção à saúde da população. No entanto, para a sua consolidação, devem ser consideradas os diversos fatores que influenciam nesse processo, como: políticas institucionais, gestores e cultura local. Assim, o SUS poderá contar, de fato, com mais uma estratégia terapêutica e promotora de saúde.

\section{REFERÊNCIAS}

1. BRASIL. Ministério da Saúde. Portaria ํㅜ 971, de 3 de maio de 2006. Aprova a Política Nacional de Práticas Integrativas e Complementares (PNPIC) no Sistema Único de Saúde. Diário Oficial da União, Brasília, DF, 4 maio 2006a. Seção 1, p. 20. Disponível em: <http://www.saude.ba.gov.br/wpcontent/uploads/2020/02/Portaria_n_971_2006__PNPIC.pdf.>. Acesso em: 20 Out. 2020.

2. FERRAZ IS, et al. Expansão das práticas integrativas e complementares no brasil e o processo de implantação no sistema único de saúde. Enfermería Actual de Costa Rica, San José, 2020; 38, 196-208.

3. HABIMORAD PHL, et al. Potencialidades e fragilidades de implantação da Política Nacional de Práticas Integrativas e Complementares. Ciênc. Saúde coletiva, Rio de Janeiro, 2020; 25(2), 395-405. 
RESUMO SIMPLES: Relato de Experiência

Título: Sinais e sintomas de ansiedade em meio à pandemia: um relato de experiência sobre a aplicação de Reiki a distância como forma de redução do sofrimento

Autora/Co-autores: Cláudia Maria de Souza Gonçalves ${ }^{1}$, Bruna Moreira da Silva ${ }^{1}$, Marcela Regina Azevedo de Castro Oliveira1, Maria Eduarda Figueiredo Santos' ${ }^{1}$, William Alves Bueno1.

Instituição: Universidade Federal de São João del-Rei - Campus Centro Oeste (UFSJ-CCO)1.

Palavras-chave: Reiki, Pandemia, Saúde Mental.

\section{INTRODUÇÃO}

O Reiki ("energia universal vital") é uma técnica oriental, que visa promover o equilíbrio físico, mental e espiritual a partir da imposição das mãos, sendo uma Prática Integrativa e Complementar em Saúde (PICS) presente no SUS que propicia o bem-estar integral, acessível e sem contraindicações médicas (BRASIL, 2018). Em meio à pandemia de COVID-19, surgiram inúmeros desafios psíquicos para lidar com o isolamento social e as incertezas acerca desse período (PEREIRA MD, et al., 2020). Assim, o uso de PICS que aliviem dores e sofrimento, principalmente nesse contexto, se faz importante na promoção do cuidado holístico e integral (BILLOT M, et al., 2019).

\section{OBJETIVO}

Relatar a experiência da aplicação de Reiki em meio à pandemia de COVID-19, por membros de uma liga universitária, à pessoa com sinais e sintomas de ansiedade, em prol de possíveis benefícios no bem-estar geral propiciado por tal prática.

\section{RELATO DE EXPERIÊNCIA}

Foi realizada a aplicação de Reiki em pessoas interessadas no recebimento gratuito, diário e ininterrupto de tal PICS, promovida todas as manhãs por membros, reikianos, de uma Liga Acadêmica mineira e coletados, virtualmente, relatos voluntários dos envolvidos. MBCO, apresentava sinais e sintomas de ansiedade percebidos em decorrência do atual contexto pandêmico. Ao longo dos três meses de recebimento de Reiki foram despertados sentimentos ambivalentes, de modo a incitar sensações pouco percebidas. Inicialmente, houve uma inquietude que gerava medo, tristeza, raiva e culpa, sendo tais desconfortos descritos como parte do processo de autoconhecimento. Gradualmente, os sentimentos negativos foram se desfazendo e novas emoções foram despertadas, dentre as quais: reconhecimento, compaixão, perdão, gratidão e tranquilidade. Assim, após a exteriorização de emoções ambíguas, MBCO alcançou uma compreensão emocional manifestando o sentimento de alívio e de amor próprio antes não notados. Desse modo, houve uma correlação entre o envio de Reiki, o reconhecimento emocional e o reestabelecimento do equilíbrio mental e do bem-estar geral, efetivando o objetivo promovido por tal prática.

\section{CONSIDERAÇÕES FINAIS}

A aplicação de Reiki a distância pode auxiliar na redução de sinais e sintomas de ansiedade, por meio da exteriorização de sentimentos que contribuem para a aquisição de um autocontrole emocional. Sendo assim, 
é indispensável mais estudos acerca do tema que se mostra promissor, de baixo custo e de grande contribuição à saúde pública.

\section{REFERÊNCIAS}

1. BILLOT M, et al. Reiki therapy for pain, anxiety and quality of life. BMJ supportive \& palliative care, 2019; 9(4): 434-438.

2. BRASIL. Ministério da Saúde. Manual de implantação de serviços de práticas integrativas e complementares. $2018 . \quad$ Disponível em: http://189.28.128.100/dab/docs/portaldab/publicacoes/manual_implantacao_servicos_pics.pdf. Acessado em: 06 de outubro de 2020.

3. PEREIRA MD, et al. The COVID-19 pandemic, social isolation, consequences on mental health and coping strategies: an integrative review. Research, Society and Development, 2020; 9(7), e652974548. 


\section{AGRADECIMENTOS}

Aos professores orientadores do evento, aos palestrantes, aos organizadores, aos autores de resumos e aos participantes do evento.

Agradecemos por tornar possível a construção deste I Congresso Acadêmico de Práticas Integrativas e Complementares em Saúde (ConAPICS) Brasil 2020 